\title{
Architectural Design Criteria for f- Block Metal Ion Sequestering Agents-Final Report
}

\section{Principal Investigator}

B. P. Hay

\section{Co-Investigators}
D. A. Dixon
R.D. Rogers ${ }^{(\mathrm{b})}$
G. J. Lumetta
J. E. Hutchison ${ }^{(\mathrm{c})}$
B. M. Rapko
R. T. Paine ${ }^{(\mathrm{d})}$
D. M. Roundhill ${ }^{(a)}$
K. N. Raymond ${ }^{(\mathrm{e})}$

May 2000

Prepared for

the U.S. Department of Energy

under Contract DE-AC06-76RLO 1830

Pacific Northwest National Laboratory

Richland, Washington 99352
(a) Texas Tech University
(b) University of Alabama

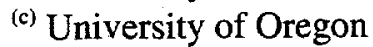
(d) University of New Mexico

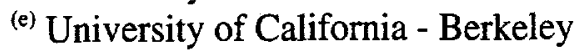




\section{DISCLAIMER}

This report was prepared as an account of work sponsored by an agency of the United States Government. Neither the United States Government nor any agency thereof, nor any of their employees, make any warranty, express or implied, or assumes any legal liability or responsibility for the accuracy, completeness, or usefulness of any information, apparatus, product, or process disclosed, or represents that its use would not infringe privately owned rights. Reference herein to any specific commercial product, process, or service by trade name, trademark, manufacturer, or otherwise does not necessarily constitute or imply its endorsement, recommendation, or favoring by the United States Government or any agency thereof. The views and opinions of authors expressed herein do not necessarily state or reflect those of the United States Government or any agency thereof. 


\section{DISCLAIMER}

Portions of this document may be illegible in electronic image products. Images are produced from the best available original document. 


\section{Executive Summary}

Critical tasks in the cleanup of U.S. Department of Energy (DOE) sites include processing radioactive wastes for disposal in long-term storage, remediation/restoration of environmental sites resulting from radioactive contamination, and decontamination/ decommissioning of nuclear facilities. Because the radioactive components, most of which are metals, are typically present in very low concentrations; it is desirable to remove them from the bulk of the contaminated source (process waste stream, groundwater, soil) and concentrate them to minimize the volume of radioactive material destined for permanent subsurface disposal and thus minimize disposal costs. As the cleanup problem continues to be defined and regulatory limits continue to decrease, ever-increasing demands will be placed on separation technologies for metallic radionuclides. Another important aspect of the site cleanup is the characterization, detection, and monitoring of radionuclides in mixed waste, ground water, contaminated soils, and process streams. The current technology, which involves collection of samples and subsequent laboratory analysis in a remote location, is extremely time and labor intensive. This drives the widespread need for portable, real-time, in situ metal ion sensors.

Organic ligands, i.e., chelating or sequestering agents, with a high degree of metal ion specificity are essential precursors for the development of both separation processes and sensors for radionuclides. In this context, there is a large group of scientists involved in a global effort to discover new ligands. Much of this work, funded by various nuclear agencies, involves the synthesis of novel organic molecules and the study of their reactivity toward metal ions. The objective is to obtain very high selectivity - the ability to discriminate between the target metal(s) and the other metals that may be present in the matrix. Ligand development is the process of synthetically connecting groups of donor atoms to form multidentate binding sites. The way that the donor atoms are connected, i.e., the architecture of the ligand, can have a dramatic impact on the resulting reactivity and selectivity toward metals. For most types of donor atoms, there is no method to predict these structural effects prior to synthesis. Thus, the current state of the art in ligand development remains largely an Edisonian enterprise, a challenging and labor-intensive process. A rational and directed approach toward ligand development would significantly reduce expenditure of both the time and resources needed to address a growing list of site needs (see Appendix A).

The objective of this project is to facilitate the ligand development process for f-block metal ions, i.e., the actinides and lanthanides, by developing an accurate set of criteria for the design of ligand architectures. To achieve this objective we first combine theory and experiment to understand the nature of fundamental interactions in selected metal-ligand systems. These design criteria provide a basis for proposing improved ligand architectures. We then incorporate this understanding within the framework of a molecular mechanics force field to allow the rapid calculation of geometries and energies for ligands and their metal complexes. This computational model provides a method for quickly screening proposed architectures to identify the best candidates for subsequent synthesis and testing.

There are a number of donor groups that have a known affinity for the f-block metal ions including amides, phosphine oxides, pyridine $\mathrm{N}$-oxides, and catecholates. To maximize the use of our resources, we decided to focus on only one type of donor group. We selected amides because (1) of the amount of existing experimental data on this class of molecules, (2) the ease of synthesis, (3) the availability of molecular mechanics parameters for amides, and (4) the current interest in amide bearing ligands as actinide extractants, e.g., the TRUEX process (actinide separation process under testing for use in tank waste cleanup at Idaho National Engineering and Environmental Laboratory) and DIAMEX (actinide separation process under development in Europe for treatment of commercial nuclear reprocessing wastes). 
Our objective was achieved with respect to the amide donor group. An accurate set of criteria for the design and evaluation of multi-dentate amide ligands were developed. Experimental research resulted in the synthesis and characterization of amide ligands and amide-metal complexes as well as the generation of structure-function data through the study of f-block metal ion binding affinities using solvent extraction and solution calorimetry. Theoretical research involved the use of electronic structure calculations for the detailed analysis of the shapes and energetics of both amides and their metal complexes. A molecular mechanics model that rapidly predicts the geometries and energetics of amides and their complexes with all metal ions in the Periodic Table, including the actinides and lanthanides, was developed and validated. Application of this model revealed that diamide structures currently used as metal ion sequestering agents in solvent extraction systems, i.e., malonamide derivatives, are poorly organized for chelation. Our results indicate that alternate diamide architectures could yield significant increases in binding affinity for the trivalent actinides. For example, we identified a novel diamide architecture that is predicted to enhance the Am(III) binding affinity by four orders of magnitude.

This project was a collaborative effort between Pacific Northwest National Laboratory and five universities: Texas Tech University, The University of Alabama, The University of Oregon, The University of New Mexico, and The University of California, Berkeley. One Ph.D. dissertation on the synthesis, characterization of calixarenes and their use in heavy metal ion extractions resulted from this research effort. Our publications and presentations received international attention by scientists interested in f-element separations for nuclear fuel reprocessing. We had three unsolicited visits from researchers working for foreign nuclear agencies to exchange data and to discuss the possibility of scientific collaboration. 


\section{Table of Contents}

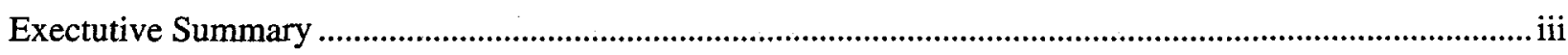

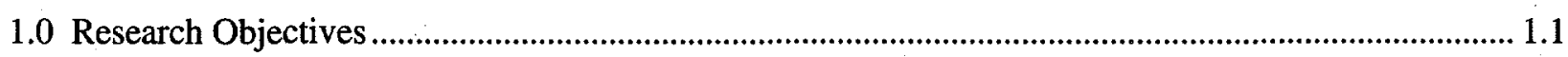

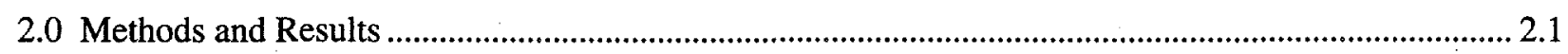

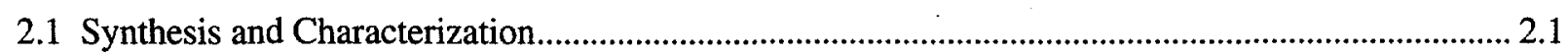

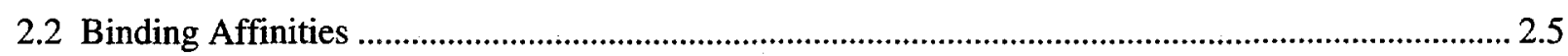

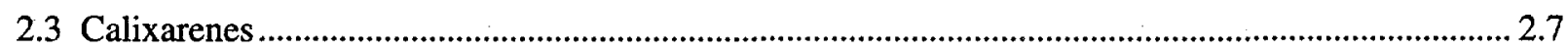

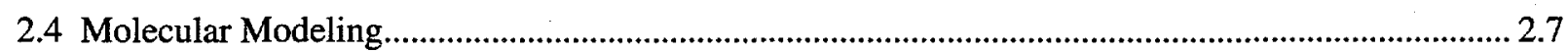

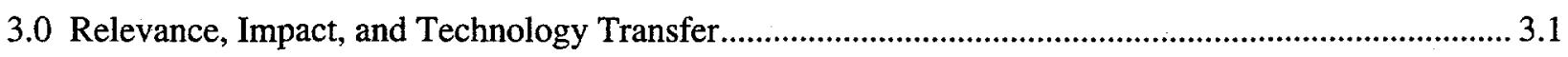

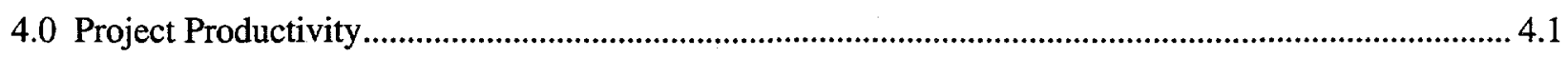

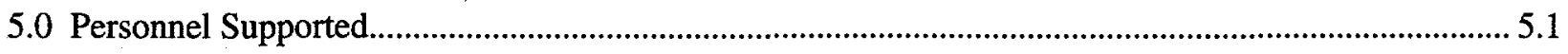

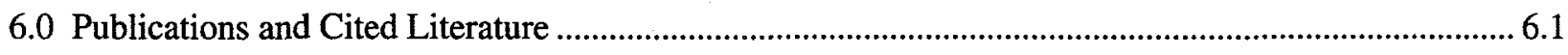

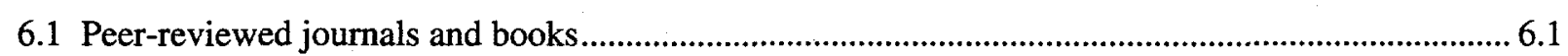

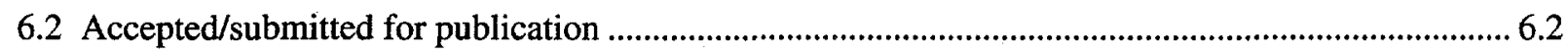

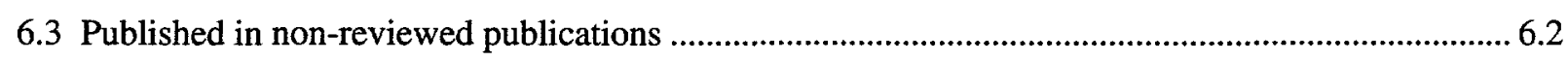

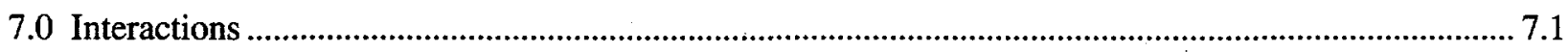

7.1 Participation/presentations at meetings, workshops, conferences.................................................. 7.1

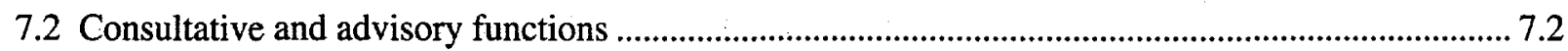

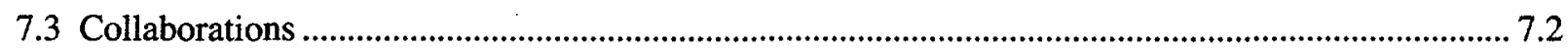

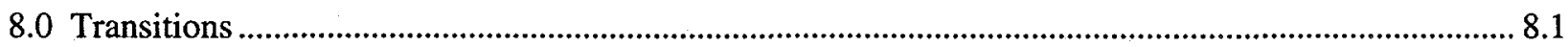

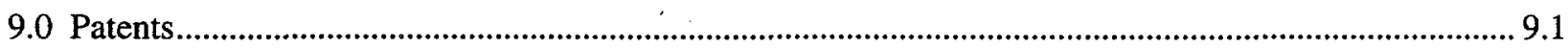

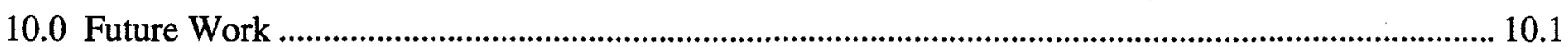

Appendix A: Year 2000 Site Technology Needs Potentially Impacted by this Research......................... A.1 


\section{Figures}

1 Diamides prepared at Pacific Northwest National Laboratory and University of Oregon 2.1

2 Single-crystal $x$-ray structures determined for f-block metal complexes with malonamides 2.2

3 Single-crystal $\mathrm{x}$-ray structures determined for f-block metal complexes with succinamides 2.4

4 Extraction constants for $\mathrm{UO}_{2} \mathrm{~L}_{2}\left(\mathrm{NO}_{3}\right)_{2}$ as a function of nitrate concentration 2.6

5 Amide-substituted calixarenes prepared at Texas Tech University... 2.7

6 Illustration of the $\mathrm{Csp}^{2}-\mathrm{Csp}^{3}$ bond rotations investigated in simple amides 2.8

7 The two forms of $\mathrm{N}, \mathrm{N}, \mathrm{N}^{\prime}, \mathrm{N}^{\prime}$-tetramethylmalonamide

8 Structures of DMF dimers showing the $\mathrm{C}-\mathrm{H} \cdots \cdot \mathrm{O}$ hydrogen bonds.

9 Illustration of preferred metal ion orientations with respect to the amide donor

10 All stable conformations of 1 and 2 when coordinated with Am(III)

11 Illustration of the most stable ligand conformations for 1,2 , and a preorganized diamide

\section{Tables}

$1 \mathrm{M}+\mathrm{L}->\mathrm{ML}$ formation constants for $\mathrm{Eu}\left(\mathrm{ClO}_{4}\right)_{3}$ in $10 \% \mathrm{DMSO} / 90 \%$ acetonitrile

2 Extraction constants at 3.0 $\mathrm{M} \mathrm{NaNO}_{3}$ 


\subsection{Research Objectives}

The objective of this project is to facilitate the ligand development process for $\mathrm{f}$-block metal ions, i.e., the actinides and lanthanides, by developing an accurate set of criteria for the design of ligand architectures. To achieve this objective we first combine theory and experiment to understand the nature of fundamental interactions in selected metal-ligand systems. This yields structural design criteria that will provide a basis for proposing improved ligand architectures. We then incorporate this understanding within the framework of a molecular mechanics force field to allow the rapid calculation of geometries and energies for ligands and their metal complexes. This computational model provides a method for quickly screening proposed architectures to identify the best candidates for subsequent synthesis and testing.

There are a number of donor groups that have a known affinity for the f-block metal ions including amides, phosphine oxides, pyridine $\mathrm{N}$-oxides, and catecholates. Scoping studies were performed on these ligands during the first year of the project, FY 1997. A decision was made to focus solely on amides. Ligands containing the amide functional group are currently used in DIAMEX (an actinide separation process used for treatment of commercial reprocessing wastes) and TRUEX (actinide separation process under testing for use in tank waste cleanup at Idaho National Engineering and Environmental Laboratory).

The DIAMEX process uses a diamide ligand as the actinide extractant. Diamides such as malonamide and succinamide contain two oxygen donor groups and can form bidentate complexes. A bidentate ligand is the simplest case in which the issue of binding site organization arises. There are three structural variables that can affect binding site organization in a diamide: the length of the bridge between the two amides, the degree of bridge alkylation, and the steric bulk of the alkyl groups attached to the nitrogen. Understanding the effect of these structural variables on metal ion complexation provides criteria for optimizing the performance of multidentate amide ligands. In collaboration with the University of Alabama and the University of Oregon, our research focused on the synthesis and characterization of diamides and their complexes, the development and application of methods to measure ligand binding affinities for f-block metals, and the development and application of molecular models to these ligands and their metal complexes. In a parallel effort, Professor D. Max Roundhill prepared series of multidentate calixarenes substituted with hydroxyl, alkoxyl, amide, and amine donor groups, and studied their behavior as metal ion extractants. 


\subsection{Methods and Results}

\subsection{Synthesis and Characterization}

We prepared diamides 1-14 in multigram quantities (see Figure 1). Compounds 5, 7, 8, 12, 13, and 14 are previously unreported. All were characterized by ${ }^{1} \mathrm{H}$ and ${ }^{13} \mathrm{C}$ nuclear magnetic resonance (NMR) spectroscopy, infrared (IR) spectroscopy, and gas chromatography-mass spectrometry (GC-MS). These diamides represent three types of structural variation. The bridge length is varied in 1 and 2 , and in 3 and 4. The degree of bridge alkylation is varied in 1,5 , and 6 , in 3,7 and 8 , in 9 and 10 , in 11 and 12 , and in 4 and 13. The steric bulk of the alkyl groups attached to the nitrogen is varied in $1,3,9,11$, and 14 , in 5 , 7 , and 12, and in 6 and 8 .

Yaried Mridge Lxigth
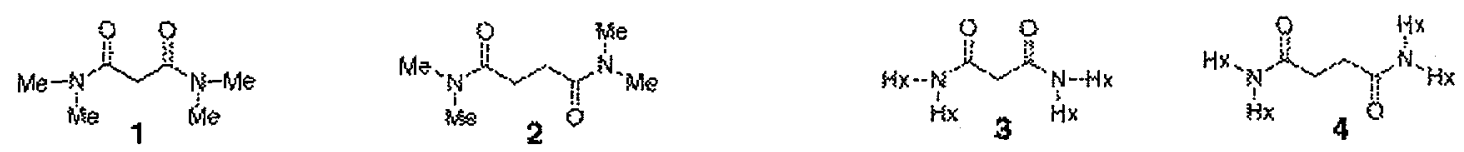

\section{Faried Bridge Alky kation}
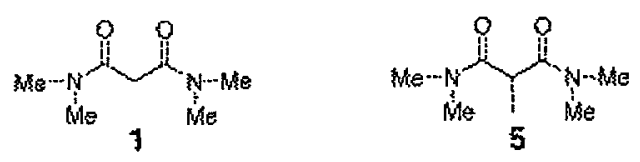<smiles>CN(C)C(=O)C(C)(C)C(=O)N(C)O</smiles>

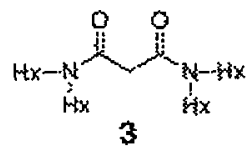<smiles>[3H]C(CNC)C(=O)NC</smiles><smiles>[2H]C([2H])([2H])C(=O)NC(C)=O</smiles><smiles>CN(C)C(=O)CC(=O)N(C)Br</smiles><smiles>CC(C)CC(C(=O)N(C)C)C(=O)N(C)C</smiles><smiles>CNC(=O)CCC(=O)NC</smiles><smiles>NC(=O)C1C2C=CC(C2)C1C(N)=O</smiles>

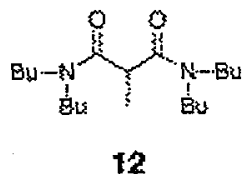

31

Yayied N-Alkylatikn<smiles>CN(C)C(=O)CC(=O)N(C)C</smiles><smiles>CN(C)C(=O)CC(=O)N(C)C</smiles>

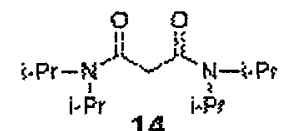

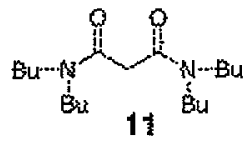<smiles>CNC(=O)CC(N)=O</smiles><smiles>CN(C)C(=O)C(S)C(=O)N(C)O</smiles><smiles>[Y7]C([18O])C(=O)C(=O)N(Br)Br</smiles><smiles>CN(N)C(=O)C(C)(C)C(=O)N(C)N</smiles>

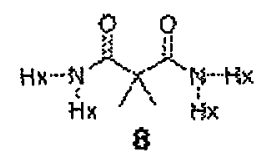<smiles>[Z]C(C(=O)NN)C(=O)NNC</smiles>

Figure 1. Diamides prepared at Pacific Northwest National Laboratory and University of Oregon 
We explored the coordination chemistry of diamides with lanthanides with emphasis on the parent compounds 1 and 2 (Lumetta et al. 1999a; McNamara et al. 1999; Rapko et al. 1999; Lumetta et al. 2000; Rapko et al. 2000). Solid-state structural information was obtained by thermogravimetric analysis (TGA) and by single-crystal x-ray diffraction at the University of Alabama in the laboratory of Professor R. D. Rogers. The question of whether the solid state structures are maintained in solution was addressed through IR spectroscopy.

TGA analysis reveals that the reaction of lanthanide nitrates with 1 yields 2:1 ligand-to-metal species for all the lanthanides examined ( $\mathrm{La}, \mathrm{Nd}, \mathrm{Gd}, \mathrm{Dy}, \mathrm{Yb}$, and $\mathrm{Lu}$ ). Titrations of lanthanide nitrates with 1 or 3 are consistent with the formation of a 2:1 species in acetonitrile solution as evidenced by the Fourier transform infrared (FTIR) spectra. No evidence for any higher L:M species is observed under these conditions.

We determined the first crystal structures for complexes of 1 with lanthanide nitrates (see Figure 2). The x-ray structures for $\mathrm{La}, \mathrm{Nd}$, and $\mathrm{Gd}$ reveal monomeric complexes with two bidentate chelating diamides. The $\mathrm{La}$ and $\mathrm{Nd}$ complexes are isostructural and have the same butterfly arrangement of the two malonamide chelates that has been observed with other malonamide derivatives.
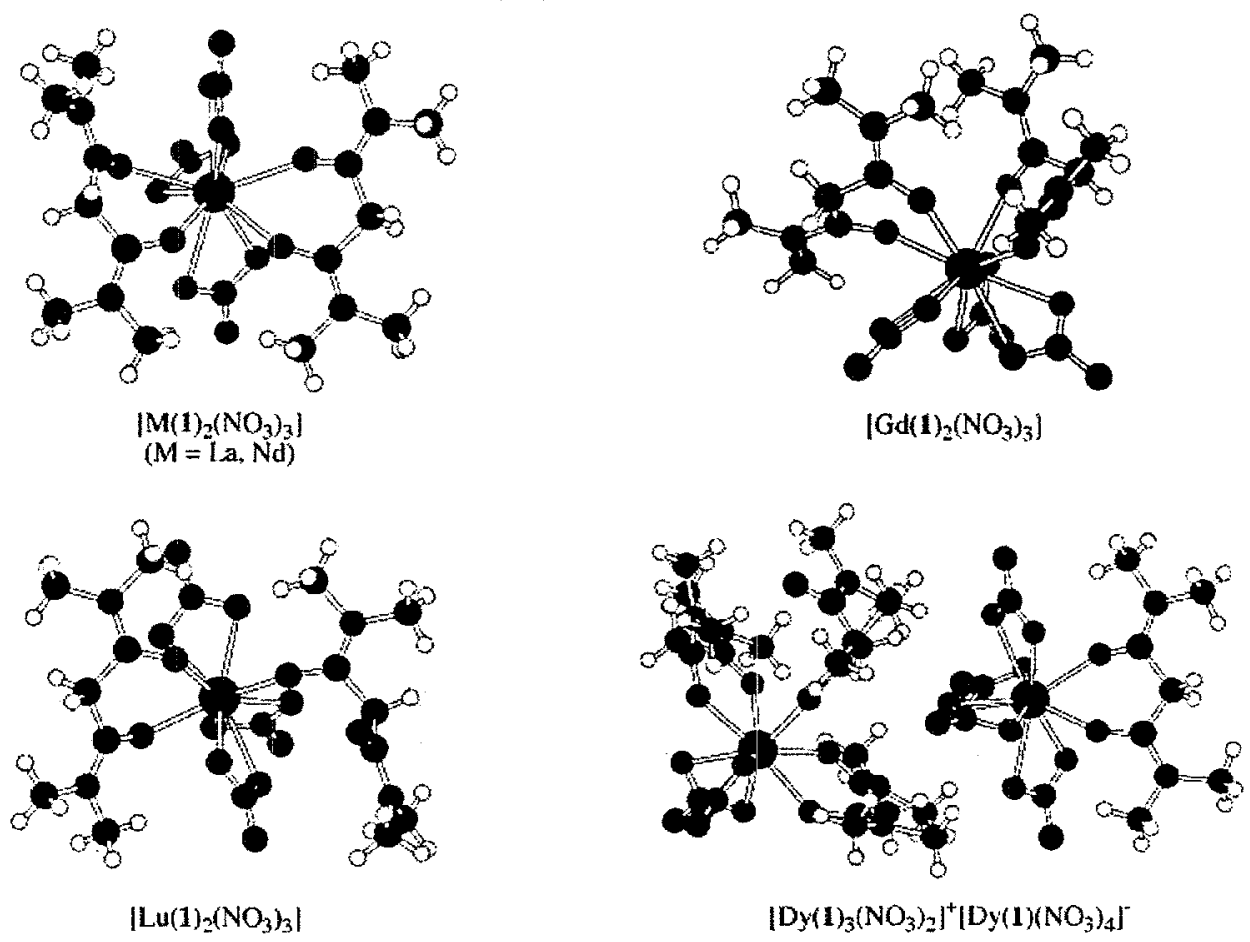

$\left[\mathrm{Dy}(\mathrm{I})_{3}\left(\mathrm{NO}_{3}\right)_{2}\right]^{+}\left[\mathrm{D} \text { y }(\mathrm{I})\left(\mathrm{NO}_{3}\right)_{4}\right]^{-}$
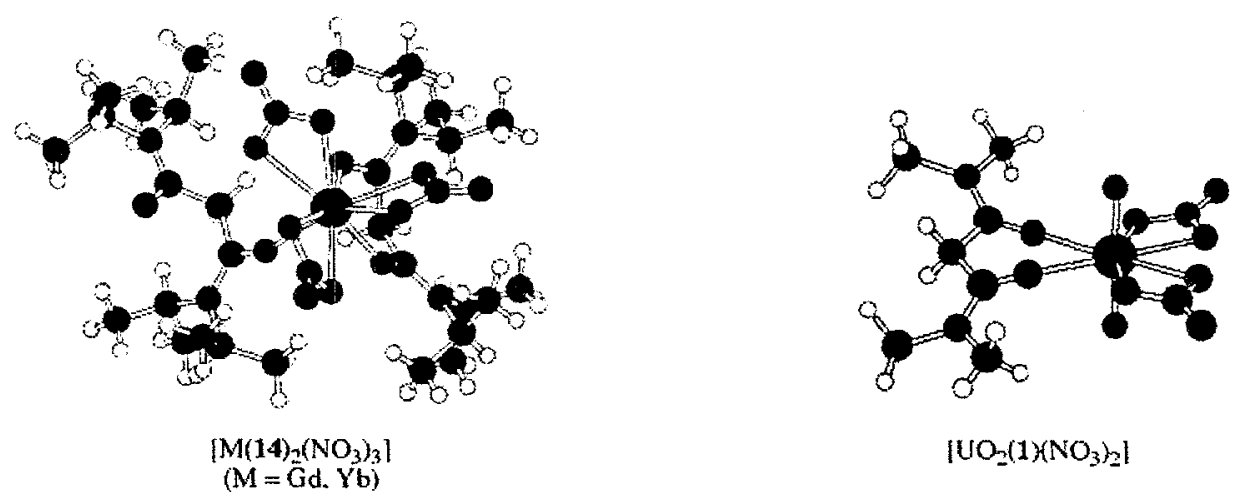

$1 \mathrm{UO}_{2}(1)\left(\mathrm{NO}_{3}\right)_{2} \mid$

Figure 2. Single crystal $x$-ray structures determined for f-block metal complexes with malonamides 
The Gd complex forms a structural isomer different from the La and $\mathrm{Nd}$ complexes. This difference lies primarily in the positioning of the ligands. In the $\mathrm{La}$ and $\mathrm{Nd}$ complexes the two bidentate diamides are positioned on opposite hemispheres of an equator defined by three bidentate nitrates. In the $\mathrm{Gd}$ complex, the two bidentate malonamides are on one side of the metal and the three bidentate nitrates are on the other.

The Dy complex with 1 differs markedly from the earlier lanthanides in the ligand arrangement. Here a disproportionation occurs between two formally 2:1 ligand-to-metal complexes to form a cationic species comprised of two bidentate diamides, one monodentate diamide and two bidentate nitrates, and an anionic species comprised of four bidentate nitrates and one bidentate diamide. The mixed monodentate and bidentate coordination found in the Dy cationic species has not been previously observed in any metal malonamide chemistry. The Lu compound shares some features with both the La and Dy compounds. It is in structure very similar to the La compound except, like the Dy compound, the metal is bonded to both a bidentate diamide and a monodentate diamide. It should be noted that despite the differing structures, each of the four types of isolated structures maintains the same 2:1 ligand-to-metal stoichiometry.

We determined the first crystal structures for complexes of 14 with lanthanide nitrates (see Figure 2). Both the $\mathrm{Gd}$ and $\mathrm{Yb}$ compounds possess the same structure. These compounds have the same 2:1 ligandto-metal stoichiometry observed with $\mathbf{1}$, but the structure is different from any observed with 1 . The complex is comprised of one bidentate diamide, one monodentate diamide, and three bidentate nitrates. Although $\mathrm{Lu}$ exhibits the same connectivity with 1 , the structures of $\left[\mathrm{Ln}(14)_{2}\left(\mathrm{NO}_{3}\right)_{3}\right]$ differ from $\left[\mathrm{Lu}(1)_{2}\left(\mathrm{NO}_{3}\right)_{3}\right]$ in the location of the diamide ligands.

We obtained a crystal structure for $\left[\mathrm{UO}_{2}(\mathbf{1})\left(\mathrm{NO}_{3}\right)_{2}\right]$, which is the first crystal structure solved for any actinide-malonamide complex. The structure consists of two bidentate nitrates and one bidentate diamide coordinated to the $\mathrm{UO}_{2}{ }^{2+}$ ion. The complex $\left[\mathrm{UO}_{2}(\mathbf{1})_{2}\right](\mathrm{OTf})_{2}(\mathrm{OTf}=$ triflate $)$ was isolated as a crystalline solid, however we were unable to obtain an x-ray structure on this material. The complex $\left[\mathrm{UO}_{2}(3)_{2}\right]^{2+}$ was prepared as the $\mathrm{BF}_{4}{ }^{-}$salt, but this material tended to form an oil. Comparison of the FTIR spectra of these complexes to the spectra of complexes formed in liquid-liquid extraction systems supports the hypothesis that complexes of the type $\left[\mathrm{UO}_{2}\left(\mathrm{NO}_{3}\right)_{2} \mathrm{~L}\right]$ and $\left[\mathrm{UO}_{2}(\mathrm{~L})_{2}\right]\left(\mathrm{NO}_{3}\right)_{2}(\mathrm{~L}=$ diamide extractant $)$ form during solvent extraction [Lumetta et al. 2000].

We obtained a series of crystal structures for complexes of lanthanides with 2 (see Figure 3 ). These are the first crystal structures for any lanthanide succinamide complex and reveal that lengthening the bridge leads to a rich and varied coordination chemistry. TGA analyses revealed that a 2:1 ligand-tometal species occurs only with the early lanthanides (La and Ce). Single crystal x-ray diffraction revealed a polymeric material with one chelating bidentate diamide bound solely to one metal and the second bridging between two metals. IR spectroscopic titration of lanthanide nitrates with 2 is consistent with the formation of a 2:1 species in solution with no evidence for any higher ligand-to-metal stoichiometries.

TGA analysis reveals a different stoichiometry with a 3:2 ligand-to-metal ratio for complexes of 2 with the lanthanides $\mathrm{Pr}, \mathrm{Nd}, \mathrm{Gd}, \mathrm{Yb}$, and $\mathrm{Lu}$. The structures of the $\mathrm{Pr}, \mathrm{Nd}, \mathrm{Gd}$, and $\mathrm{Yb}$ compounds were determined by single crystal $\mathrm{x}$-ray diffraction and were found to be dimeric, with one bidentate diamide bound to a single metal and a bidentate diamide bridging two metals [Rapko et al. 1999]. With the exception of $\mathrm{La}$ and $\mathrm{Ce}$, IR spectroscopic titration of lanthanide nitrates with $\mathbf{2}$ or $\mathbf{4}$ is consistent with the formation of the 3:2 species in solution with no evidence for any higher ligand-to-metal species. Ce appears to be a special (and transitional) lanthanide in its reaction with 2. Although IR and TGA analysis indicate it is predominantly the 2:1 ligand-to-metal product, crystals for both the 2:1 and 3:2 compound were isolated. No evidence was found for multiple stoichiometries with any of the other lanthanides.

If noncoordinating counteranions are present, such as triflate or perchlorate, TGA analysis of the products formed in the presence of excess 2 reveals a 4:1 ligand-to-metal complex with Eu and Nd. 
Single crystal $\mathrm{x}$-ray diffraction revealed a monomeric species with four bidentate chelating diamides [Rapko et al. 2000]. IR spectroscopic titration of lanthanide perchlorates with 2 is consistent with the formation of a 4:1 species in solution with no evidence for any higher ligand-to-metal species. However, this stoichiometry is very sensitive to the amount of water present. By controlling the concentration of water, it is possible to isolate mixed aqua/diamide complexes such as those shown in Figure 3.

The reaction of excess 2 with thorium nitrate in methanol allowed the isolation and crystallization of a compound with a 3:2 ligand-to-thorium ratio. Although this stoichiometry is also observed for the reaction of 2 with most of the lanthanide nitrates, structure determination revealed that this compound disproportionates to form $\left[\mathrm{Th}\left(\mathrm{NO}_{3}\right)_{6}\right]^{2-}$ and $\left[\mathrm{Th}(2)_{3}\left(\mathrm{NO}_{3}\right)_{2}\right]^{2+}$. Here all nitrates and diamides are bidentate.
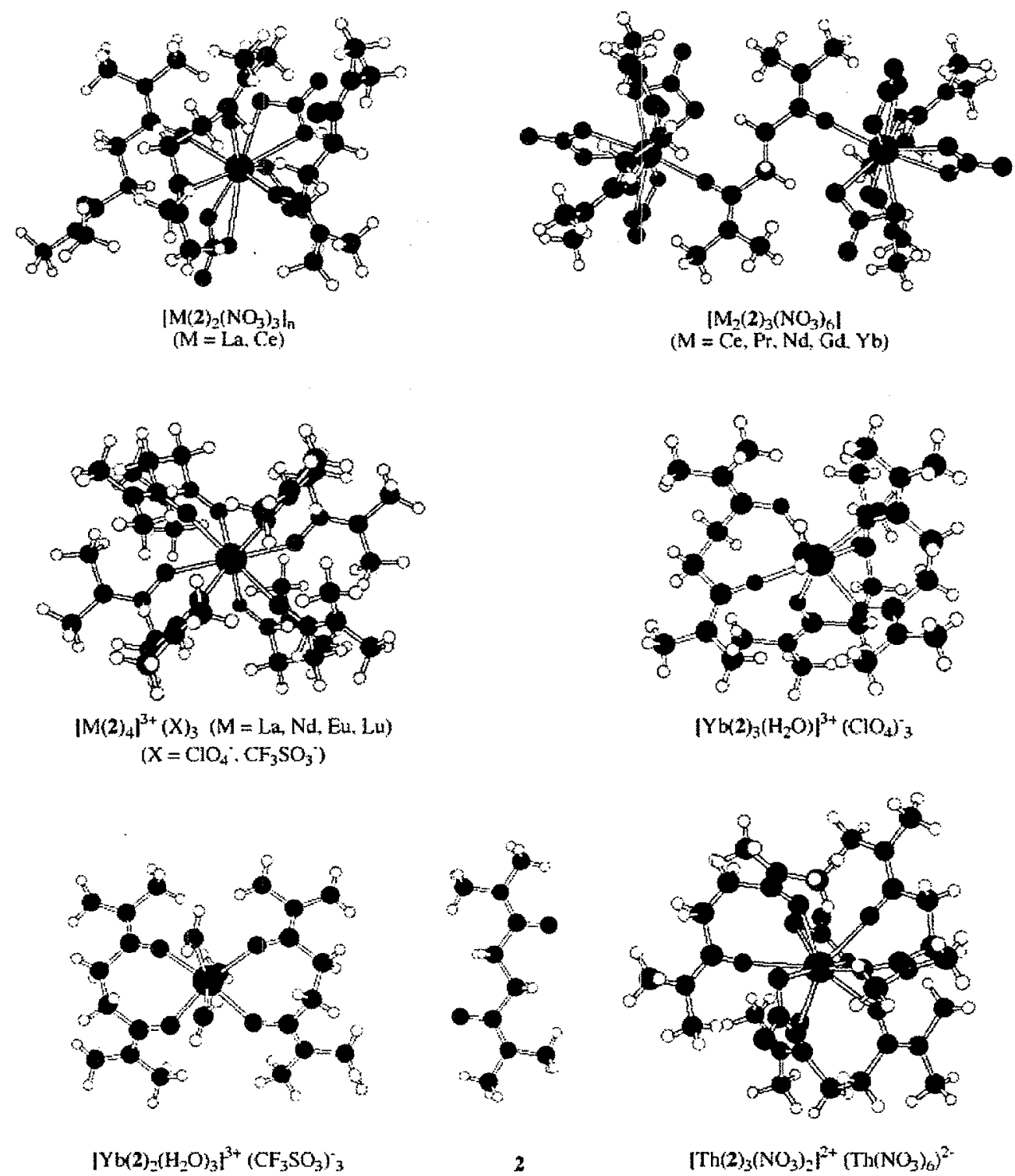

$\mathrm{Yb}(2)_{2}\left(\mathrm{H}_{2} \mathrm{O}_{3} \mathrm{I}^{3+}\left(\mathrm{CF}_{3} \mathrm{SO}_{3}\right)_{3}\right.$

2

Figure 3. Single crystal $\mathrm{x}$-ray structures determined for $\mathrm{f}$-block metal complexes with succinamides 


\subsection{Binding Affinities}

A literature search was performed to locate any information regarding single-phase stability constants for amide complexes of lanthanides or actinides and solution structural information on such complexes. This search revealed that not only are there no existing structure-stability data sets but no stability constant data for $f$-block metal ions with pure amide ligands. Given that the amide group is neutral over a wide $\mathrm{pH}$ range, this situation reflects the general difficulty of determining stability constants for nonionizable ligands. Generation of structure-function data require that the relative metal binding affinities should be determined under identical experimental conditions of solvent, counter ion, and temperature. A variety of methods for the determination of metal-amide binding constants were investigated in first year of this project. These methods include electronic spectroscopy, IR spectroscopy, ion selective electrodes, calorimetry, and solvent extraction. Of these methods, solvent extraction and calorimetry were found to be the most promising.

\section{,}

Calorimetry has yielded preliminary measurements of diamide formation constants with Eu which represent the first direct thermodynamic binding affinity measurements for any metal amide complex. The formation constants for 1:1 ligand:metal complexes were determined for $\mathrm{Eu}\left(\mathrm{ClO}_{4}\right)_{3}$ with 1, 2, 3, 8, 9, and 14 in $10 \% \mathrm{DMSO} / 90 \%$ acetonitrile solution buffered to ionic strength $0.1 \mathrm{M}$ at $25^{\circ} \mathrm{C}$. The results are presented in Table $\overline{1}$. A decrease in the formation constant by a factor of 3.7 occurs on lengthening the bridge by one methylene group, as shown in the comparison of 1 and 2 . A comparison of 3 and 8 shows that dialkylation of the methylene bridge causes a drop in the formation constant of at least 2 orders of magnitude. Data for $1,3,9$, and 14 illustrate that the formation constant steadily decreases as the steric bulk of $\mathrm{N}$-alkyl groups increases.

Table 1. $\mathrm{M}+\mathrm{L} \rightarrow \mathrm{ML}$ formation constants for $\mathrm{Eu}\left(\mathrm{ClO}_{4}\right)_{3}$ in $10 \% \mathrm{DMSO} / 90 \%$ acetonitrile

\begin{tabular}{|c|c|c|}
\hline Ligand & Formation Constant, $\mathrm{M}^{-1}$ & $( \pm 3 \sigma)$ \\
\hline 1 & 21.9 & $(1.1)$ \\
\hline 2 & 5.9 & (1.2) \\
\hline 3 & 3.5 & (1.3) \\
\hline 8 & $<0.1$ & \\
\hline 9 & 11.0 & $(1.2)$ \\
\hline 14 & 1.2 & $(1.2)$ \\
\hline
\end{tabular}

Solvent extraction also yielded structure-function data for diamide complexes with europium and uranyl nitrates. We developed a new computer program, the SX Solver, to analyze solvent-extraction equilibria [Lumetta et al. 1999b]. The program operates out of Microsoft Excel and uses the built-in "Solver" to minimize the sum of the square of the residuals between measured and calculated distribution coefficients. The program has been used to analyze europium and uranyl extraction data (see below).

We investigated the extraction of europium(III) nitrate from aqueous acidic nitrate solutions with a series of tetrahexylmalonamides, 3, 7, and 8, in t-butylbenzene [McNamara et al. 1999]. These ligands allowed a systematic determination of the effects of alkyl substitution at the methylene carbon. Equilibrium modeling of the extraction data indicates that there is only one species present in all cases, EuL $_{3}\left(\mathrm{NO}_{3}\right)_{3}$. The extraction constant decreases by seven-fold going from 3 to 7 . However, a precipitous drop in the extraction constant occurs going from 3 to 8 , i.e., with substitution of a second methyl group on the methylene carbon (see Table 2). This drop is consistent with the calorimetry results, suggesting the effect is due to the metal ligand interaction rather than environmental factors such as counteranion, solvent, or concentration. 
Table 2. Extraction constants at 3.0 $\mathrm{M} \mathrm{NaNO}_{3}$. The extraction constants reported for $\mathrm{Eu}(\mathrm{IIN})$ are for .formation of EuL $\left.\mathrm{ENO}_{3}\right)_{3}$ and those reported for $\mathrm{U}(\mathrm{VI})$ are for formation of $\mathrm{UO}_{2} \mathrm{~L}_{2}\left(\mathrm{NO}_{3}\right)_{2}$.

\begin{tabular}{cll}
\hline Ligand & $\mathrm{K}_{\mathrm{ex}}(\mathrm{Eu}(\mathrm{III}))$ & $\mathrm{K}_{\mathrm{ex}}(\mathrm{U}(\mathrm{VI}))$ \\
\hline 3 & 0.041 & 11.3 \\
7 & 0.0057 & 6.6 \\
8 & $<0.0002$ & 0.26 \\
\hline
\end{tabular}

The extraction of uranyl nitrate with 3 [Lumetta et al. 1999a], 4, 7, 8, 13, and $N, N$-dihexylpentamide (DHPA) in t-butylbenzene also has been investigated. Equilibrium modeling of the extraction data indicates that there are up to three different species present. These are $\mathrm{UO}_{2} \mathrm{~L}\left(\mathrm{NO}_{3}\right)_{2}, \mathrm{UO}_{2} \mathrm{~L}_{2}\left(\mathrm{NO}_{3}\right)_{2}$, and $\mathrm{UO}_{2} \mathrm{~L}_{3}\left(\mathrm{NO}_{3}\right)_{2}$. The relative population of these species depends on the nitrate concentration and the identity of the ligand. Extraction constants for the predominant $\mathrm{UO}_{2} \mathrm{~L}_{2}\left(\mathrm{NO}_{3}\right)_{2}$ species could be determined for all three ligands (see Table 2). The relative binding affinities parallel those observed for europium complexation.

Figure 4 presents the extraction constants for $\mathrm{UO}_{2} \mathrm{~L}_{2}\left(\mathrm{NO}_{3}\right)_{2}$ with various ligands as a function of nitrate concentration. These results suggest that the uranyl binding affinities for the diamide ligands follows the order $4>3>7>13>8$. The stoichiometry of the major species $\mathrm{UO}_{2} \mathrm{~L}_{2}\left(\mathrm{NO}_{3}\right)_{2}$ is inconsistent with the generally accepted bidentate coordination of the diamides and nitrates. However, this stoichiometry is consistent with the formation of complexes with monodentate-bound diamides. Several other lines of evidence support this supposition. It is sterically impossible to form a complex with two bidentate nitrates and two bidentate malonamide chelate rings. If the nitrates are inner-sphere coordinated there is room for only two inner-sphere amide oxygens and this is the connectivity observed in all $\mathrm{UO}_{2}\left(\mathrm{NO}_{3}\right)_{2}$ amide complexes. Yet, 3 gives the same extraction stoichiometry observed with monoamides.

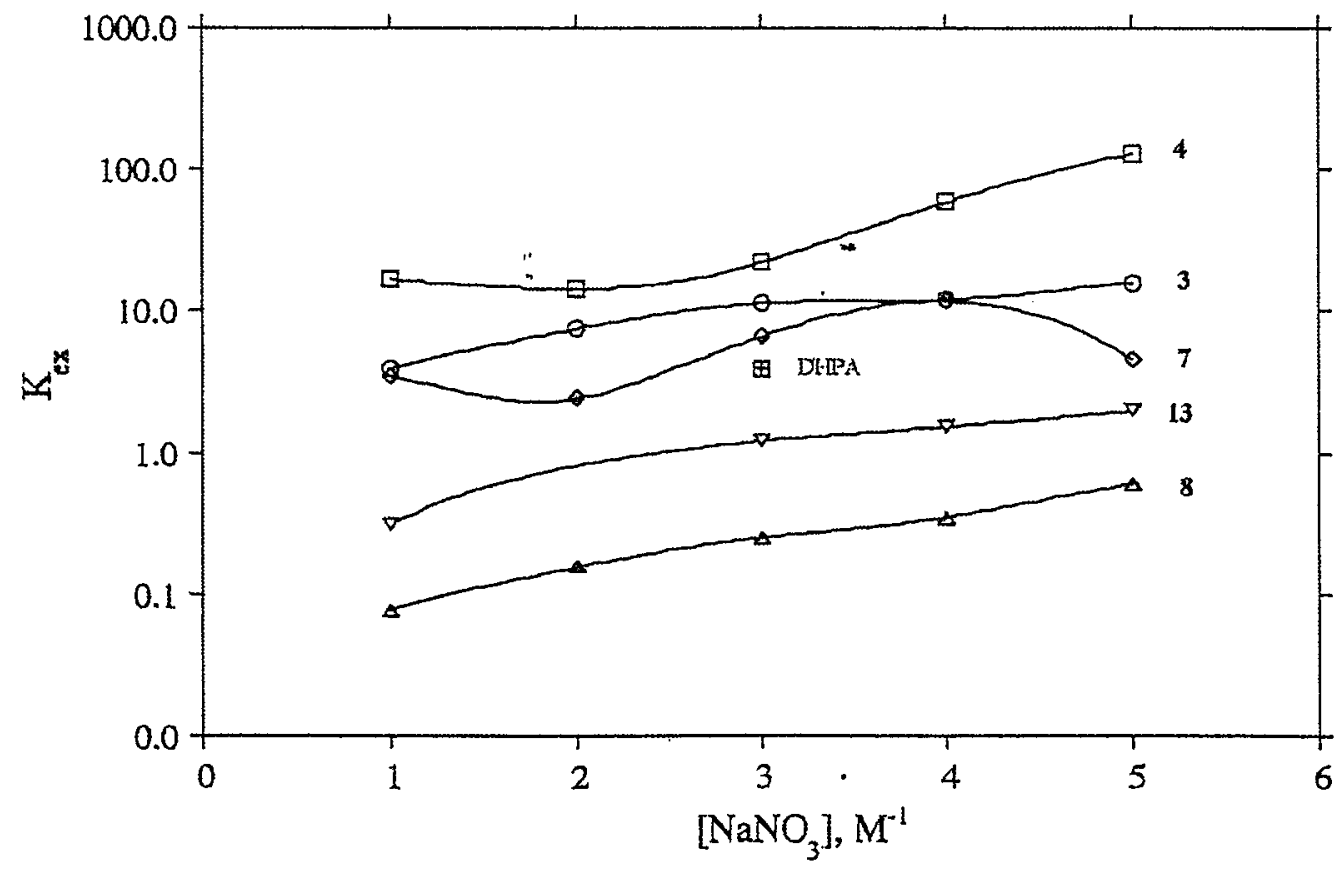

Figure 4. Extraction constants for $\mathrm{UO}_{2} \mathrm{~L}_{2}\left(\mathrm{NO}_{3}\right)_{2}$ as a function of nitrate concentration 
Although there are no structurally characterized examples of $\mathrm{UO}_{2}\left(\mathrm{NO}_{3}\right)_{2}$ complexes with monodentate malonamide or succinamide ligands, our structures of sterically hindered Ln complexes reveal that monodentate coordination is possible. Molecular modeling studies reveal that bidentate diamide chelation requires significant ligand reorganization, destabilizing the complex by $\geq 6.0 \mathrm{kcal} / \mathrm{mol}$, respectively (vide infra).

In accord with the well-known chelate effect, a bidentate ligand should exhibit binding constants several orders of magnitude greater than a monodentate ligand. Under identical experimental conditions we find that the extraction constant for DHPA (at $3 \underline{\mathrm{M} \mathrm{NaNO}}$ ) is roughly the same as that for 7 and is only about a factor of six less than that for 4. This lack of a chelate effect is consistent with monodentate coordination of the malonamides. An alternate explanation is that the two diamides exhibit bidentate coordination and in so doing displace the nitrates from the inner-coordination sphere. In this case the gain from the chelate effect would be offset by the unfavorable formation of "free" nitrate ion in the organic phase. Under DIAMEX process conditions, FTIR evidence is consistent with the presence of a species containing two inner-sphere bidentate diamide ligands [Lumetta et al. 2000].

\subsection{Calixarenes}

Nine calixarene amide derivatives, 15-23 in Figure 5, were prepared and characterized in the laboratory of Professor Roundhill at Texas Tech University [Falana et al. 1998; Wolf et al. 1999]. Solidphase structures for two of these compounds were determined by single crystal $\mathrm{x}$-ray diffraction [Wolf et al. 1999]. Geometrically isomeric 1,2- and 1,3-tert-butylcalix[4]arene amides di-substituted with (dibutylcarbamoyl)methoxy groups were structurally characterized by ${ }^{1} \mathrm{H}$ and ${ }^{13} \mathrm{C}$ nuclear magnetic resonance (NMR) spectroscopy [Falana et al. 1998]. Two non-interconverting conformers of the 1,2isomer were isolated. The 1,3-isomer and the two 1,2-isomers were used to extract the uranyl ion into toluene and isooctane. The degree of the extraction depended on the particular conformer of the calixarene. As highlighted in a science/technology concentrate in $C \& E$ News (March 2, 1998), this is the first example in which such conformer effects on the extraction of the uranyl ion are observed. The utility of calixarene amides and other calixarene derivatives as extractants for heavy metals was investigated [Yordanov and Roundhill 1998; Yordanov et al. 1999; Koch and Roundhill 2000a, 2000b, 2000c; Shen et al. 2000].

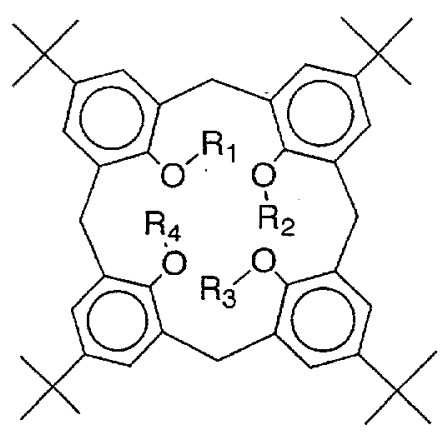

$$
\begin{aligned}
& 13 \mathrm{R}_{1}=\mathrm{R}_{2}=\mathrm{CH}_{2} \mathrm{C}(\mathrm{O}) \mathrm{N}(\mathrm{nBu})_{2}, \mathrm{R}_{3}=\mathrm{R}_{4}=\mathrm{H} \\
& 14 \mathrm{R}_{1}=\mathrm{R}_{3}=\mathrm{CH}_{2} \mathrm{C}(\mathrm{O}) \mathrm{N}(\mathrm{nBu})_{2}, \mathrm{R}_{2}=\mathrm{R}_{4}=\mathrm{H} \\
& 15 \mathrm{R}_{1}=\mathrm{R}_{2}=\mathrm{CH}_{2} \mathrm{C}(\mathrm{O}) \mathrm{NH}_{2}, \mathrm{R}_{3}=\mathrm{R}_{4}=\mathrm{H} \\
& 16 \mathrm{R}_{1}=\mathrm{R}_{2}=\mathrm{CH}_{2} \mathrm{C}(\mathrm{O}) \mathrm{NEt}_{2}, \mathrm{R}_{3}=\mathrm{R}_{4}=\mathrm{H} \\
& 17 \mathrm{R}_{1}=\mathrm{R}_{2}=\mathrm{CH}_{2} \mathrm{C}(\mathrm{O}) \mathrm{NEt}_{2}, \mathrm{R}_{3}=\mathrm{R}_{4}=\mathrm{Me} \\
& 18 \mathrm{R}_{1}=\mathrm{CH}_{2} \mathrm{C}(\mathrm{O}) \mathrm{NEt}_{2}, \mathrm{R}_{2}=\mathrm{R}_{3}=\mathrm{iPr}, \mathrm{R}_{4}=\mathrm{H} \\
& 19 \mathrm{R}_{\mathrm{L}}=\mathrm{R}_{2}=\mathrm{R}_{3}=\mathrm{R}_{4}=\mathrm{CH}_{2} \mathrm{C}(\mathrm{O}) \mathrm{NH}_{2} \\
& 20 \mathrm{R}_{1}=\mathrm{R}_{2}=\mathrm{R}_{3}=\mathrm{R}_{4}=\mathrm{CH}_{2} \mathrm{C}(\mathrm{O}) \mathrm{NEt}_{2} .
\end{aligned}
$$

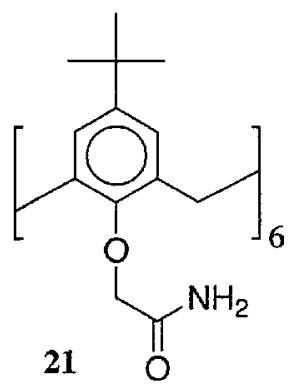

Figure 5. Amide substituted calixarenes prepared at Texas Tech University

\subsection{Molecular Modeling}

To understand how ligand architecture affects metal ion complexation, it is imperative to first understand the structural features of the free ligand. Given the importance of the amide functional group 
in organic chemistry and biochemistry, we were surprised to discover how little was known about the shape of simple amides and diamides. We found that the widely used and extensively validated MM3 model failed to reproduce observed ligand conformations. To address this problem, we first performed $a b$ initio DFT and molecular orbital theory calculations to obtain the rotational potential surfaces for Csp ${ }^{2}$ $\mathrm{Csp}^{3}$ bond rotation in acetamide, propanamide, 2-methylpropanamide, and 2,2-dimethylpropanamide (see Figure 6). These data were used to correct the MM3 model. The refined model now predicts the correct shapes for amides [Sandrone et al. 1999a]

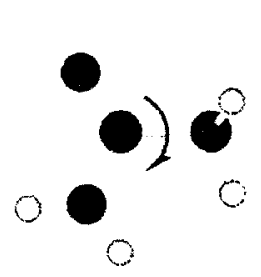

acetamide

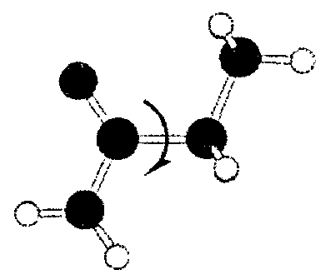

propanamide

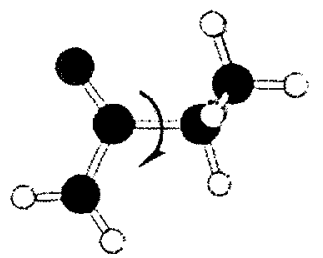

2-methylpropanamide

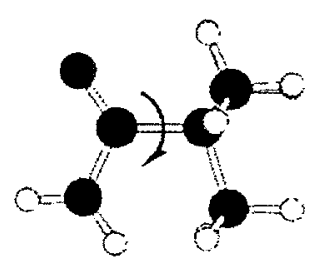

2.2-dimethylpropanamide

Figure 6. Illustration of the $\mathrm{Csp}^{2}-\mathrm{Csp}^{3}$ bond rotations investigated in simple amides

The default MM3 force field does not contain torsional parameters needed to describe bond rotations present in malonamides. Ab initio DFT and molecular orbital theory calculations were performed to identify all stable geometries and relative energies of malonamide, the three geometric isomers of N,Ndimethylmalonamide, and $N, N, N^{\prime}, N^{\prime}$-tetramethylmalonamide, 1 [Sandrone et al. 1999b]. Only one of the ten resulting structures had been previously reported. The two conformers of $\mathbf{1}$ are shown in Figure 7. These data were used to derive the missing MM3 parameters. We also examined the conformations of $\mathrm{N}, \mathrm{N}, \mathrm{N}^{\prime} \mathrm{N}^{\prime}$-tetramethylsuccinamide, 2, (a) to identify the low energy shapes of this ligand and (b) to provide a further benchmark for the MM3 model performance [Vargas et al. 2000b]. Electronic structure calculations were performed on 20 minima. Structures for the three most stable forms are shown in Figure 7. MM3 and DFT/DZVP structures and energies were in general agreement. However, the energies of several MM3 conformations were significantly different than those from electronic structure calculations. Examination of these cases led to the discovery of a previously unrecognized intra-diamide interaction.

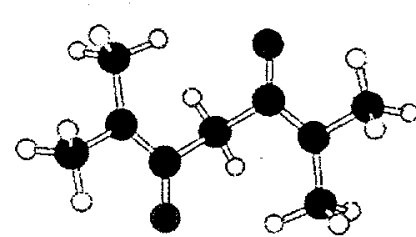

$0.0 \mathrm{kcal} / \mathrm{mol}$

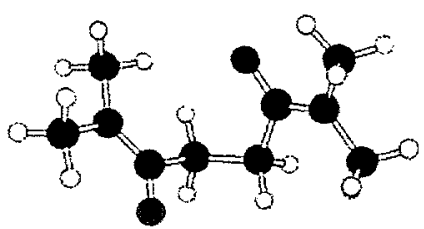

$0.0 \mathrm{kcal} / \mathrm{mol}$

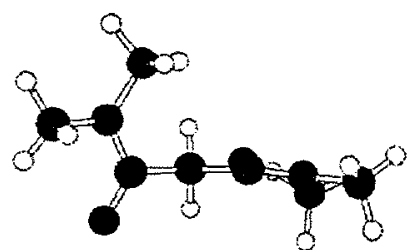

$2.84 \mathrm{kcal} / \mathrm{mol}$

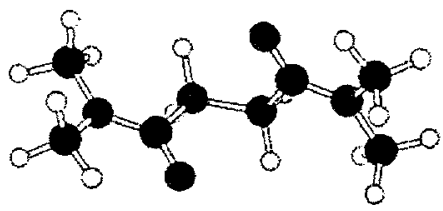

$0.03 \mathrm{kcal} / \mathrm{mol}$

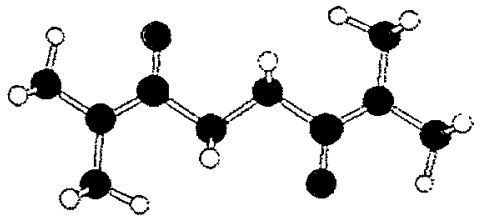

$1.00 \mathrm{kcal} / \mathrm{mol}$

Figure 7. The two forms of $\mathrm{N}, \mathrm{N}, \mathrm{N}^{\prime}, \mathrm{N}^{\prime}$-tetramethylmalonamide, 1, and three lowest energy forms of $\mathrm{N}, \mathrm{N}, \mathrm{N}^{\prime}, \mathrm{N}^{\prime}$-tetramethylsuccinamide, 2 , at the MP2/DZVP level of theory 
Discrepancies between MM3 and DFT/DZVP energies in the succinamide structures occurred when there were close contacts $(\leq 2.3 \AA)$ between the methyl hydrogens and the oxygen atoms. This suggested the possibility of intramolecular hydrogen bonding between these groups. To test this hypothesis, calculations were performed on dimers of the dimethylformamide, DMF (see Figure 8). The results confirm the presence of $\mathrm{C}-\mathrm{H} \cdot \bullet \mathrm{O}=\mathrm{C}$ hydrogen bonds. The electronic dissociation energy per hydrogen bond, $2.0 \mathrm{kcal} / \mathrm{mol}$, was unexpectedly strong. Structural features of the $\mathrm{C}-\mathrm{H} \cdot \bullet \mathrm{O}=\mathrm{C}$ hydrogen bonds in DMF dimers are similar to those observed between peptide chains in proteins. A correlation between proton acidity and $\mathrm{C}-\mathrm{H} \cdots \mathrm{O}$ bond strength yields an estimate of $4 \mathrm{kcal} / \mathrm{mol}$ for the electronic dissociation energy of the protein $\mathrm{C}_{\alpha}-\mathrm{H} \cdot \cdots \cdot \mathrm{O}=\mathrm{C}$ hydrogen bond. The magnitude of this interaction, roughly $1 / 2$ the strength of the $\mathrm{N}-\mathrm{H} \cdots \cdots \mathrm{O}=\mathrm{C}$ hydrogen bond, suggests that $\mathrm{C}-\mathrm{H} \cdots \cdots \mathrm{O}=\mathrm{C}$ hydrogen bonding interactions represent a hitherto unrecognized, significant contribution in the determination of protein conformation [Vargas et al. 2000a]. These data were used to add the C-H $\cdots O \mathrm{O}$ interaction to the MM3 model.
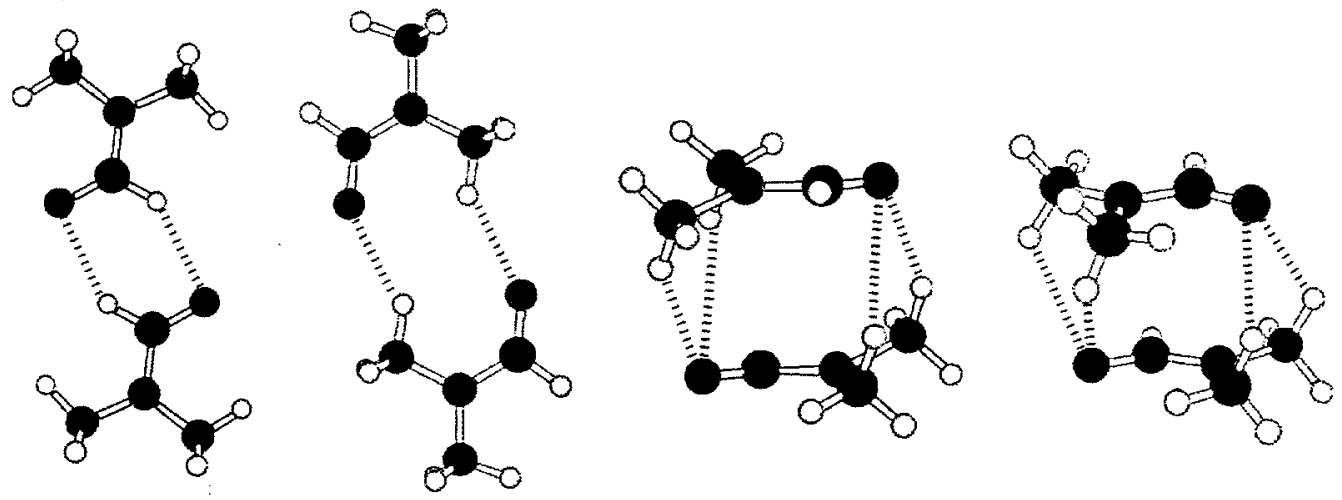

Figure 8. Structures of DMF dimers showing the $\mathrm{C}-\mathrm{H} \cdots \mathrm{O}$ hydrogen bonds. Proteins exhibit hydrogen bonding with structural features very similar to the two structures shown on the right.

After modifying the MM3 parameter set to reproduce the electronic structure calculation results on simple amides and diamides, we developed further MM3 parameters for metal-amide interactions. Because the design of selectivity involves both an affinity for the target metal and rejection of competing metal ions, the MM3 model needed to be applicable not only to f-block metals but to other metals as well. For this reason, our model was designed to evaluate amide complexes with metal ions throughout the periodic table. Initial parameters obtained through electronic structure calculations were refined to give the best fit to crystal structures. An exhaustive survey of the Cambridge Structural Database identified suitable metal-amide structures for MM3 parameter refinement and validation. In addition, a statistical analysis of bond lengths, bond angles, and torsion angles was performed as a function of the degree of alkylation of the amide functional group and the type of metal ion in the amide complex. Geometric preferences of the coordinated amide ligand were evaluated in terms of $\mathrm{M}-\mathrm{O}-\mathrm{C}$ bond angles and M-O-C$\mathrm{N}$ torsion angles. This evaluation led to the first recognition of the geometric requirements for amide binding [Clement et al. 1998]. A marked difference was observed in the structural features of covalent metals versus ionic metals (Figure 9). With the covalent metals, the M-O-C angle is close to $120^{\circ}$ as would be expected for optimal interaction with the oxygen $\mathrm{sp}^{2}$ orbital. With the ionic metals, the M-O-C angle approaches $155^{\circ}$ consistent with an optimal orientation with the amide dipole. This structural difference suggests that ligand architecture can be manipulated to optimize selectivity for the actinides over the transition metals.

The performance of the extended MM3 model for metal-amide complexes has been validated by comparison of calculated and observed structural features. Fifty-six crystal structures, including the eighteen determined in this project, were used in this comparison. In addition to f-block metal ions [lanthanides, Th(IV), U(IV), U(VI)], this set of structures included complexes with alkali, alkaline earth, 


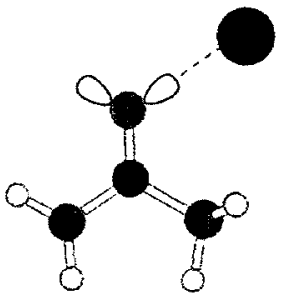

covalent metal

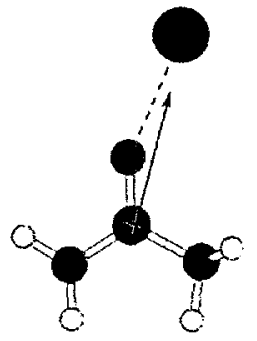

ionic metal

Figure 9. Illustration of preferred metal ion orientations with respect to the amide donor

and transition metals. A unique feature of the MM3 parameterization is that all metal-dependent parameters are correlated with the ionic radius, charge, and electronegativity of the metal ion. Thus the resulting MM3 model can be applied to any metal ion for which these properties are known. For the 56 crystal structures examined to date, the model computes a mean average deviation of $\pm 0.035 \AA$ for $\mathrm{M}-\mathrm{O}$ bond lengths, $\pm 5^{\circ}$ for M-O-C angles, and $\pm 15^{\circ}$ for M-O-C-X torsion angles (X $=\mathrm{H}, \mathrm{C}$, or $\mathrm{N}$ ) [Hay et al. 1999].

Additional model validation has been provided by a detailed conformational analysis of simple diamide chelate rings (see Figure 10). The model predicts three stable conformations for the malonamide chelate ring, and four stable conformations for the succinamide ring, when coordinated with a trivalent f-block metal ion, e.g. Am(III). These predictions are consistent with $\mathrm{x}$-ray crystal structure data. Comparison with experiment reveals that the model not only correctly predicts all observed forms, but, in addition, the correctly predicts the most frequently observed conformations are the lowest energy forms.

Stable chelate rings of 1

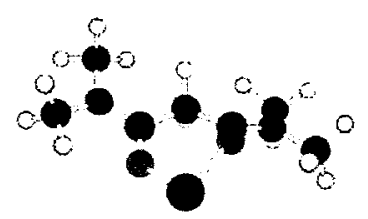

$0 \mathrm{kcal} / \mathrm{mol}$

19 in Xray

Stable chelate rings of 2

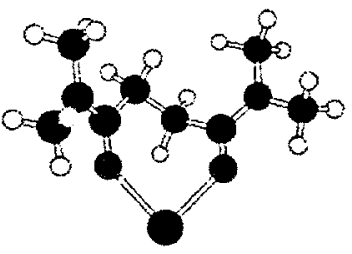

$0 \mathrm{kcal} / \mathrm{mol}$

27 in Xray

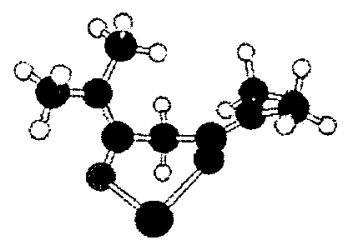

$0.7 \mathrm{kcal} / \mathrm{mol}$

2 in Xray

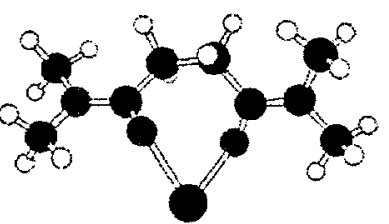

$0.4 \mathrm{kcal} / \mathrm{mol}$

1 in Xray

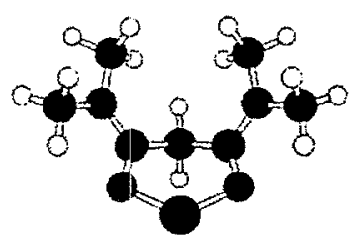

$3.3 \mathrm{kcal} / \mathrm{mol}$

2 in Xray

Figure 10. All stable conformations of 1 and 2 when coordinated with Am(III). In each case, the calculated relative ligand strain energies agree with the frequency that these chelate conformations are observed in crystal structures of lanthanide complexes. 
Examination of malonamide and succinamide chelate rings in complexes with the f-block metal ions reveals that the oxygen donor atoms in these architectures are poorly organized for complexation. Significant structural reorganization is required to achieve a binding conformation and the binding conformation does not provide the optimal orientation of either amide with respect to the metal ion. These results suggest that alternative ligand architectures, in which the diamide was organized for chelation, could yield significant increases in metal ion binding affinity. Using the criteria developed in this study, we designed a diamide architecture (Figure 11) that is both preorganized for complexation and offers binding sites that are complementary for the trivalent actinides and lanthanides. Synthesis of this new diamide was underway until the conclusion of the project at the University of Oregon in the laboratory of Prof. J. E. Hutchison.

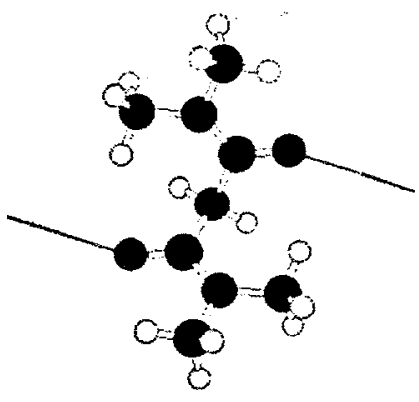

1

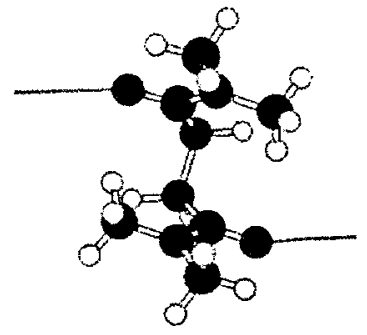

2

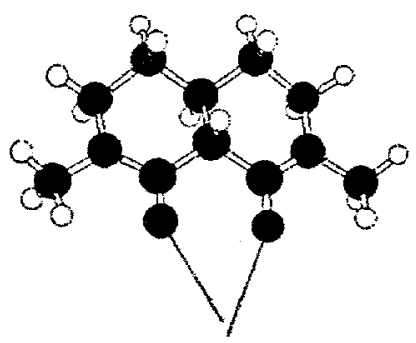

new architecture

Figure 11. Illustration of the most stable ligand conformations for 1,2 , and a preorganized diamide (right). Vectors emanating from the oxygens show the optimal line of metal ion approach to each of the amide oxygens. Chelation to a trivalent f-block metal ion, e.g. Am(III), by malonamide or succinamide requires significant structural reorganization, destabilizing the complex by $7.6 \mathrm{kcal} / \mathrm{mol}$ and $6.0 \mathrm{kcal} / \mathrm{mol}$, respectively. In contrast, chelation by the preorganized diamide requires minimal structural reorganization, $0.1 \mathrm{kcal} / \mathrm{mol}$. 


\subsection{Relevance, Impact, and Technology Transfer}

- How does this new scientific knowledge focus on critical DOE environmental management problems? How will the new scientific knowledge generated by this project improve technologies and cleanup approaches to significantly reduce future costs, schedules, and risks and meet DOE compliance requirements?

- Metal ion separations and sensors require metal-selective binding sites. By facilitating the development of highly effective and selective ligands for the f-block metal ions, this scientific knowledge will lead to the rapid discovery of the sequestering agents needed to develop separation processes and sensors for the actinides and lanthanides. Year 2000 Site technology needs that could benefit from this research are listed in Appendix A.

- To what extent does the new scientific knowledge bridge the gap between broad fundamental research that has wide-ranging applications and the timeliness to meet needs-driven applied technology development?

- Clearly, we are at the fundamental end of the spectrum. However, by working with groups that are on the technology development end, we can effectively bridge this gap. The PI has demonstrated this with the development of a more effective strontium ligand in collaboration with Dr. E. P. Horwitz (ANL) and, more recently, with the development of a more selective cesium ligand in collaboration with Dr. B. A. Moyer (ORNL).

- What is the project's impact on individuals, laboratories, departments, and institutions? Will results be used? If so, how will they be used, by whom, and when?

- This project provided an excellent broad training for the personnel involved. On the experimental side, students and postdoctoral associates learned synthetic methods and the use of both crystallography and spectroscopic techniques to characterize new compounds. Those involved with molecular modeling learned how to apply various computational methods to metal complexes. The technology we developed, i.e., design criteria for amide ligands and the ability to screen proposed amide ligand architectures, is ready for use now.

- What difference has the project made? Now that the project is complete, what new capacity, equipment, or expertise has been developed?

- We now have the ability to identify amide ligand architectures that will exhibit enhanced actinide and lanthanide binding before they are made.

- How have the scientific capabilities of collaborating scientists been improved?

- By working with with a national laboratory, our collaborators became aware of issues related to the DOE environmental mission. The collaboration between experimentalists and theorists helped the former gain an appreciation of the potential role of theory in designing moleules for specific applications. This led the research group at Texas Tech to buy a Silicon Graphics workstation and Spartan software package to do their own preliminary calculations. Their theoretical studies, underway for 1-2 years, have already proven beneficial to their synthetic effort.

- How has this research advanced our understanding in the area?

- We proved that computational methods can be used to understand how ligand structure affects metal ion binding and how this understanding can be used to identify improved ligand architectures.

- What additional scientific or other hurdles must be overcome before the results of this project can be successfully applied to DOE environmental problems?

- The only hurdle is the lack of sufficient funding to allow us to proceed. 
- Have any other government agencies or private enterprises expressed interest in the project?

- Yes. We had three unsolicited visits from researchers working for foreign nuclear agencies to exchange data and to discuss the possibility of scientific collaboration. These groups, listed below, have active research programs aimed at understanding and improving diamide sequestering agents for nuclear fuel reprocessing.

Dr. Marie-Christine Charbonnel and Dr. Jean-Pierre Dognon, Commissariat a L'Energie Atomique DCC/ DRRV/ SEMP, Marcoule, France visited Pacific Northwest National Laboratory to discuss possible collaboration on ligand design for f-block metal ions, November 4-5, 1998. This interaction resulted in the submission of a collaborative DOE/Nuclear Energy Research Initiative proposal in FY99. The proposal was not successful.

Dr. Jean-Pierre Dognon

CEA/Valrho (Marcoule)

DCC/DRRV/SEMP/LCTS

Bat. 166

30207 Bagnols-sur-Ceze

FRANCE

Phone: $33(0) 466796152$

E-mail: dognonjp@amandine.cea.fr
Dr. Marie-Christine Charbonnel

CEA/Valrho (Marcoule)

DCC/DRRV/SEMP/LCTS

Bat. 171

30207 Bagnols-sur-Ceze

FRANCE

Phone: $33(0) 466791609$

charbonel@amandine.cea.fr

Dr. Senji Tachimori, Japan Atomic Energy Research Institute, visited Pacific Northwest National Laboratory to discuss possible collaboration on ligand design for f-block metal ions, March 8, 1999. Dr. Tachimori presented a seminar, "Recent Progress in the Development of Novel Extractants for Actinides by Molecular Design at JAERI."

Dr. Senji Tachimori

Separation Chemistry Laboratory

Department of Materials Science

Japan Atomic Energy Research Institute

Tokai-Mura, Naka-Gun

Ibaraki-ken 319-1195

JAPAN

Phone: 81-29-282-5198

E-mail: tachi@mummy.tokai.jaeri.go.jp

Prof. Kenji Takeshita of the Tokyo Institute of Technology and Mr. Tatsuro Matsumura of the Japan Atomic Energy Research Institute visited Pacific Northwest National Laboratory to discuss mutual research interests, September 7, 1999. Both visitors presented seminars: "Gel/liquid Extraction of Lanthanide and Actinide Elements Using Polymer Gel Copolymerizing Phosphoric Acid" and "Recovery of Actinide Elements from Nuclear Liquid Wastes by Plant Biomass."

Prof. Kenji Takeshita

Department of Environmental

Chemistry and Engineering

Tokyo Institute of Technology

4259 Nagasuta, Midori-Ku

Yokohama 226-8502

JAPAN JAPAN

Phone: 045(924)5414

E-mail: takeshit@chemenv.titech.ac.jp
Mr. Tatsuro Matsumura

Research Engineer

Department of Safety Research

Japan Atomic Energy Research Institute

Tokai-Mura Naka-Gun

Ibaraki-Ken 319-1195

Phone: 81-29-282-6271

E-mail: tatsuro@nucef.tokai.jaeri.go.jp 


\subsection{Project Productivity}

- Did the project accomplish all of its goals?

- No. Our original scope included similar studies on other donor groups including phosphine oxides, pyridine $\mathrm{N}$-oxides, and catecholates. Although preliminary studies were performed with ligands bearing these groups, we decided to focus our efforts on a single donor group type. We chose the amides for reasons given above. In addition, our plans to complete a calorimetric study of amide metal binding constants were cut short by the resignation of a key staff member, Dr. Linfeng Rao, who left Pacific Northwest National Laboratory near the end of the second year of the project.

- Was the project on schedule?

- Yes. This was a level-of-effort project to conduct directed basic research. Continuous progress was made throughout the course of the project.

- Was the work plan revised?

- No. All research performed was within the scope of the original proposal. 


\subsection{Personnel Supported}

\section{Pacific Northwest National Laboratory}

Dr. Mikhail S. Alnajjar (senior research scientist)

Dr. David A. Dixon (chief scientist)

Dr. Benjamin P. Hay (staff scientist)

Dr. Gregg J. Lumetta (staff scientist)

Dr. Linfeng Rao (senior research scientist)

Dr. Brian M. Rapko (senior research scientist)

Dr. Omoshile Clement (AWU postdoctoral associate)

Dr. Rubicelia Fosada-Vargas (AWU postdoctoral associate)

Dr. Bruce K. McNamara (AWU postdoctoral associate)

Dr. Jorge Olguin-Garza (Visiting Scientist, Autonomous University of Mexico, Iztapalapa, Mexico)

Dr. Giovanni Sandrone (AWU postdoctoral associate)

Dr. Pier L. Zanonato (AWU Visiting Scientist, University of Padova, Italy)

\section{Texas Tech University}

Prof. D. Max Roundhill

Dr. H. F. Koch (postdoctoral associate)

Dr. O. M. Falana (postdoctoral associate)

Dr. J. Shen (postdoctoral associate)

Mr. N. Wolf (graduate student)

Mr. M. A. Rodriguez (graduate student)

\section{The University of Alabama}

Prof. Robin D. Rogers

Mr. Grant Broker (graduate student)

\section{The University of Oregon}

Prof. James E. Hutchison

Dr. Robert D. Gilbertson (AWU postdoctoral associate) 


\subsection{Publications and Cited Literature}

All literature cited in the Methods and Results section is presented in this section.

\subsection{Peer-reviewed journals and books}

- Falana O. M., H. R. Koch, D. M. Roundhill, G. J. Lumetta, and B. P. Hay. 1998. "Synthesis and Extraction Studies of 1,2- and 1,3-Disubstituted Butylcalix[4]Arene Amides with Oxyions: Geometric and Conformational Effects." Chem. Commun., 503-504.

- Hay B. P. and O. Clement. 1998. "Metal Complexes." Invited Book Chapter in The Encyclopedia of Computational Chemistry, P. vR. Schleyer, N. L. Allinger, T. Clark, J. Gasteiger, P. A. Kollman, H. F. Schaefer III, and P. R. Schreiner, eds. John Wiley \& Sons, Chichester.

- Clement O., B. M. Rapko, and B. P. Hay. 1998. "Structural Aspects of Metal-Amide Complexes." Coord. Chem. Rev. 170:203-243.

- Rao L., Y. Xia, B. M. Rapko, and P. F. Martin. 1998. "Synergistic Extraction of Eu(III) and Am(III) by Thenoyltrifluoroacetone and Neutral Donor Extractants: Octyl(Phenyl)-N,NDiisobutylcarbonyl-methylphosphine Oxide and 2,6-Bis(Diphenylphosphino)methyl Pyridine N,P,P Trioxide." Solv. Extr. Ion. Exch. 16: 913-929.

- Yordanov A. and D. M. Roundhill. 1998. "Solution Extraction of Transition and Post-Heavy and Precious Metals by Chelate and Macrocyclic Ligands." Coord. Chem. Rev., 170: 93-124.

- Yordanov A., N. J. Wolf, E. M. Georgiev, H. F. Koch, O. M. Falana, and D. M. Roundhill. 1999. "Derivatized Calix[4]arenes as Selective Phase Transfer Extractants for Heavy Metal and Oxyion Salts." Comm. Inorg. Chem., 20:163-175.

- Hay, B. P., O. Clement, G. Sandrone, and D. A. Dixon. 1998. "A MM3(96) Force Field for Metal Amide Complexes." Inorg. Chem., 37:5887-5894.

- Lumetta G. L., B. K. McNamara, and B. M. Rapko. 1999. "Complexation of Uranyl Ion by Tetrahexyl-malonamides: An Equilibrium Modeling and Infrared Spectroscopic Study." Inorg. Chim. Acta 293: 195-205.

- McNamara B. K., G. J. Lumetta, and B. M. Rapko. 1999. "Extraction of Europium(III) Ion with Tetrahexylmalonamides." Solv. Extr. Ion. Exch. 17:1403-1421.

- Wolf N. J., E. M. Georgiev, A. T. Yordanov, B. L. Whittlesey, H. F. Koch, and D. M. Roundhill. 1999. "Synthesis and Crystal Structures of Lower Rim Amine and Carbamoyl Substituted Calixarenes as Transfer Agents for Oxyanions Between an Aqueous and a Chloroform Phase." Polyhedron 18: 885-896.

- Rapko B. M., B. K. McNamara, R. D. Rogers, G. J. Lumetta, and B. P. Hay. 1999. "The Coordination of Lanthanide Nitrates with $N, N, N^{\prime}, N^{\prime}-$ Tetramethylsuccinamide and $N, N, N^{\prime}, N^{\prime}-$ Tetrahexylsuccinamide." Inorg. Chem., 38:4585-4592.

- Sandrone G., D. A. Dixon, and B. P. Hay. 1999a. " Amides: $\mathrm{H}_{2} \mathrm{~N}-\mathrm{C}(=\mathrm{O})-\mathrm{R}, \mathrm{R}=$ Methyl, Ethyl, i-Propyl, t-Butyl." J. Phys. Chem., A,103:993-902.

- Sandrone G., D. A. Dixon, and B. P. Hay. 1999b. "Conformational Analysis of Malonamide, $\mathrm{N}, \mathrm{N}$ '-Dimethylmalonamide, and $\mathrm{N}, \mathrm{N}, \mathrm{N}$ ', N'-Tetramethylmalonamide." J. Phys. Chem. A, 103:3554-3561.

- Hay B. P. 1999. "The Use of Molecular Mechanics in the Design of Metal Ion Sequestering Agents." Metal Separation Technologies Beyond 2000: Integrating Novel Chemistry with Processing, The Minerals, Metals, and Materials Society, Warrendale, Pennsylvania. 


\subsection{Accepted/submitted for publication}

- Koch H. F., N. J. Wolf, and D. M. Roundhill. 2000. "A Comparison Between the Picrate and Inductively Coupled Plasma-Atomic Emission Spectroscopy Methods of Metal Assays in Solution for Calix[4]arene Amides and Amines as Extractants." Sep. Sci. Tech., accepted.

- Shen J., H. F. Koch, and D. M. Roundhill. 2000. "Polyethylene Glycol as a Selective Biphasic Phase Transfer Agent for the Extraction of Chromium(VI) from Aqueous Salt Solutions." Sep. Sci. Tech., accepted.

- Koch H. F. and D. M. Roundhill. 2000a. "Lower-Rim Amide- and Amine-Substituted Calix[4]arenes as Phase Transfer Extractants for Oxyions Between an Aqueous and an Organic Phase.". Calixarene Molecules for Separations, G. J. Lumetta and R. D. Rogers, eds. ACS Symposium Series, American Chemical Society, Washington, D.C., accepted.

- Koch H. F. and D. M. Roundhill. 2000b. "Synthesis and Characterization of Calix[4]arene Functionalized Poly(ethylene glycol) Derivatives." J. Incl. Phenom. and Macrocycl. Chem., accepted.

- Vargas R., J. Garza, D. A. Dixon, and B. P. Hay. 2000a. "The Dimethylformamide Dimer: Evidence for a Strong C-H--O Interaction." J. Am. Chem. Soc., accepted.

- Vargas R., J. Garza, D. A. Dixon, and B. P. Hay. 2000b. "Conformational Analysis of $\mathrm{N}, \mathrm{N}, \mathrm{N}$ ', N'-Tetramethylsuccinamide: Importance of $\mathrm{C}-\mathrm{H} \cdots \cdot \mathrm{O}$ Hydrogen Bonds?" J. Phys. Chem., $A$, accepted.

- Hay B. P. and R. D. Hancock. 2000. "The Role of Donor Group Orientation as a Factor in Metal Ion Recognition by Ligands." Coord. Chem. Rev., accepted.

- Rapko B. M., B. K. McNamara, G. J. Lumetta, R. D. Rogers, G. Broker, and B. P. Hay. 2000. "Coordination of Lanthanide Ions Containing Non-Coordinating Counteranions with $\mathrm{N}, \mathrm{N}, \mathrm{N}$ ', N'Tetra-methylsuccinamide (TMSA) in Preparation and Characterization of [(TMSA)4Ln][A]3, A $=\mathrm{ClO}_{4}{ }^{-}, \mathrm{CF}_{3} \mathrm{SO}_{3}{ }^{-}$." Inorg. Chem., submitted.

- Lumetta G. J.;, B. K. McNamara, B. M Rapko, R. L. Sell, R. D. Rogers, G. Broker, and J. E. Hutchison. 2000. "Synthesis and Characterization of Mono- and Bis(tetraalkylmalonamide)Uranium(VI) Complexes." Inorg. Chim. Acta, submitted.

\subsection{Published in non-reviewed publications}

- Hay B. P., D. A. Dixon, G. J. Lumetta, B M Rapko, and D. M. Roundhill. 1997. In "Science to Support DOE Site Cleanup: The Pacific Northwest National Laboratory Environmental Management Science Program Awards. Fiscal Year 1997 Mid-Year Progress Report." PNNL11589, Richland, Washington.

- Hay B. P., D. A. Dixon, G. J. Lumetta, B. M Rapko, and D. M. Roundhill. 1998a. In "Science to Support DOE Site Cleanup: The Pacific Northwest National Laboratory Environmental Management Science Program Awards. Fiscal Year 1998 Mid-Year Progress Report.,, PNNL11899, Richland, Washington.

- Hay B. P., D. A. Dixon, G. J. Lumetta, and B. M. Rapko. 1998b. In "Environmental Management Science Program Workshop.” CONF-980736, Environmental Management Science Program, U.S. Department of Energy Office of Science and Risk Policy, EM-52, Washington, D.C.

- Hay B. P., D. A. Dixon, G. J. Lumetta, B. M Rapko, and D. M. Roundhill. 1999. In "Science to Support DOE Site Cleanup: The Pacific Northwest National Laboratory Environmental Management Science Program Awards. Fiscal Year 1998 Mid-Year Progress Report." PNNL12208, Richland, Washington.

- Lumetta G. J., B. M. Rapko, and B. K. McNamara. 1999. "The SX Solver: A New Computer Program for Analyzing Solvent Extraction Equilibria." PNNL-12085, Pacific Northwest National Laboratory, Richland, Washington. 
- Wolf, N. J. 1999. "Synthesis, Characterization, and Heavy Metal Liquid Extraction Studies of Xanthate Substituted Alkyl Chains and Lower-Rim Amine or Carbamoyl Substituted Calix[4]arenes." Ph.D. Thesis, available from UMI, Order No. DA 9906609, Dissertation Abstracts Int. B, 59(9) 4807. 


\subsection{Interactions}

\subsection{Participation/presentations at meetings, workshops, conferences}

- "Extraction of f-Elements by Phosphine Oxide/Pyridine N-Oxide Ligands." B.M. Rapko, 213 American Chemical Society National Meeting, San Francisco, April 1997.

- "Amide Complexes of f-Block Elements." G. J. Lumetta, B. K. McNamara, and E. Burgeson. $21^{\text {st }}$ Annual Actinide Separations Conference, Charleston, South Carolina, June 1997.

- "Synergistic Extraction of Eu(III) and Am(III) by TTA and the Neutral Donor Extractants CMPO and NOPOPO." L. Rao, Y. Xia, B. M. Rapko, and P. L. Martin, $21^{\text {st }}$ Annual Actinide Separations Conference, Charleston, South Carolina, June 1997.

- "Complexation of Eu(III) by N,N,N',N'-Tetra-alkyldiamides." P. L. Zanonato and L. Rao. $214^{\text {th }}$ American Chemical Society National Meeting, Las Vegas, September 1997.

- "Determination of Actinide and Lanthanide Binding Constants with Amides and Diamides." B. M. Rapko, G. J. Lumetta, B. K. McNamara, L. Rao, and P. L. Zanonato, Tenth Symposium on Separation Science and Technology for Energy Applications, Gatlinburg, Tennessee, October 1997.

- "A MM3(96) Force Field for Metal-Amide Complexes." O. Clement, G. Sandrone, D. A. Dixon, and B. P. Hay, $215^{\text {th }}$ American Chemical Society National Meeting, Dallas, March 1998.

- "Binding of Amide Ligands to f-Block Elements." G. J. Lumetta, B. K. McNamara, and B. M. Rapko, $22^{\text {nd }}$ Annual Actinide Separations Conference, Chattanooga, April 1998.

- "New Macrocycles for Selective Ion Exchange." D. M. Roundhill, Metals Adsorption Workshop, Cincinnati, May 1998.

- "Sulfur and Nitrogen Derivatized Calix[4]Arenes as Selective Phase Transfer Extractants for Heavy Metals and Oxyions." A. T. Yordanov, N. J. Wolf, H. F. Koch, and D. M. Roundhill, Second Fargo Conference on Main Group Chemistry, Fargo, North Dakota, June 1998.

- "A Modified MM3(96) Force Field for Simple Amides and Diamides." B. P. Hay, D. A. Dixon, and G. Sandrone, $53^{\text {rd }}$ Northwest Regional American Chemical Society Meeting, Pasco, Washington, June 1998.

- "A MM3(96) Force Field for Metal-Amide Complexes." O. Clement, G. Sandrone, D. A. Dixon, and B. P. Hay, $53^{\text {rd }}$ Northwest Regional American Chemical Society Meeting, Pasco, Washington, June 1998.

- "Coordination Chemistry of Lanthanide Salts with N,N,N',N'-Tetramethyl-succinamide and N,N,N',N'-Tetrahexyl-succinamide." B. M. Rapko, B. K. McNamara, R. D. Rogers, G. J. Lumetta, and B. P. Hay, $53^{\text {rd }}$ Northwest Regional American Chemical Society Meeting, Pasco, Washington, June 1998.

- "Binding of Diamide Ligands to f-Block Elements." G. J. Lumetta, B. K. McNamara, and B. M. Rapko, $53^{\text {rd }}$ Northwest Regional American Chemical Society Meeting, Pasco, Washington, June 1998.

- "A Modified MM3(96) Force Field for Simple Amides and Diamides." B. P. Hay, D. A. Dixon, and G. Sandrone, West Coast Theoretical Chemistry Conference, Richland, Washington, June 1998.

- “A MM3(96) Force Field for Metal-Amide Complexes." O. Clement, B. P. Hay, D. A. Dixon, and G. Sandrone, West Coast Theoretical Chemistry Conference, Richland, Washington, June 1998.

- "Architectural Design Criteria for f-Block Metal Sequestering Agents." B. P. Hay, Environmental Management Science Program Workshop, Chicago, Illinois, July 1998.

- "A Points-on-a-Sphere Approach to Model Metal-Ligand Interactions with an Extended MM3 Model." B. P. Hay, Invited Speaker, Symposium on Molecular Mechanics, $216^{\text {th }}$ American Chemical Society National Meeting, Boston, August 1998. 
- "Thermodynamics of Europium(III) Complexation with Alkyl-Substituted Diamides in Organic Solvents." L. Rao, P. Zanonato, and P. Di Bernardo, $216^{\text {th }}$ American Chemical Society National Meeting, Boston, August 1998.

- "Ligand Design with Molecular Mechanics." B. P. Hay, Invited Speaker, INEEL Science Integrated Workshop, Environmental Management Science Program, Idaho Falls, October 1998.

- "Coordination Chemistry of Tetraalkyldiamides with f-Block Metal Salts." B. M. Rapko, B. K. McNamara, R. D. Rogers, G. J. Lumetta, G. Broker, and B. P. Hay, $217^{\text {th }}$ American Chemical Society National Meeting, Anaheim, March 1999.

- "Equilibrium Modeling of the Extraction of f-Block Elements by Diamides." G. J. Lumetta, B. K. McNamara, and B. M. Rapko, 217 $7^{\text {th }}$ American Chemical Society National Meeting, Anaheim, March 1999.

- $\quad$ "Calixarene Amines and Amides as Extractants for Oxyions." D. M. Roundhill, $217^{\text {th }}$ National American Chemical Society National Meeting, Anaheim, March 1999.

- "Coordination Chemistry of Diamides with f-Block Metal Salts." B. M. Rapko, B. K. McNamara, R. D. Rogers, G. J. Lumetta, G. Broker, and B. P. Hay, Metal Separation Technologies Beyond 2000: Integrating Novel Chemistry with Processing, United Engineering Foundation Conference, Turtle Bay, Oahu, Hawaii, June 1999.

- "The Application of Molecular Mechanics in the Design of Metal Ion Sequestering Agents." B. P. Hay, Invited Speaker, Metal Separation Technologies Beyond 2000: Integrating Novel Chemistry with Processing, United Engineering Foundation Conference, Turtle Bay, Oahu, Hawaii, June 1999.

- "Ligand Design by Molecular Mechanics - Recent Developments." B. P. Hay, Invited Speaker, SERMACS-99, South East Regional American Chemical Society Meeting, Knoxville, Tennessee, October 1999.

- "Building a Better Mousetrap: Improved Host Design through Molecular Modeling." B. P. Hay, Invited Speaker, Chemistry Division Seminar Series, Argonne National Laboratory, Chicago, December 1999.

- "Ligand Design with Molecular Mechanics." B. P. Hay, Invited Speaker, I\&EC Symposium on Molecular Mechanics, $219^{\text {th }}$ American Chemical Society Meeting, San Francisco, March 2000.

- "Coordination Chemistry of Tetraalkyldiamides with f-Block Metal Salts." B. M. Rapko, G. J. Lumetta, B. K. McNamara, B. P. Hay, R. D. Rogers, and G. Broker, $219^{\text {th }}$ American Chemical Society Meeting, San Francisco, March 2000.

\subsection{Consultative and advisory functions}

None.

\subsection{Collaborations}

- Texas Tech University: Prof. D. Max Roundhill received funding from this project to synthesize and characterize novel functionalized calix[4]arenes and, to study their metal ion binding properties.

- The University of Alabama: Mr. Grant Broker received funding from this project under the supervision of Prof. Robin D. Rogers. His contribution was to obtain x-ray crystal structures of $f$ block metal ion diamide complexes prepared at PNNL.

- The University of Oregon: Dr. Robert D. Gilbertson received funding from this project under the supervision of Prof. James E. Hutchison. His contribution was the synthesis and characterization of amide and diamide molecules used in studies at PNNL.

- The University of California-Berkeley: Prof. Ken N. Raymond provided structural information and metal binding constant data for tris-catechol and tris-hydroxypyridinone ligands. No funding was supplied to UC-Berkeley for this collaboration. 
- The University of New Mexico: Prof. Robert T. Paine provided structural information on various novel pyridine $\mathrm{N}$-oxide/phosphine oxides and their metal complexes. No funding was supplied to UNM for this collaboration. 


\subsection{Transitions}

Efficient and selective metal sequestering agents are key components in separation processes and sensors. U.S. Department of Energy Site Technology Coordination Groups have extensively documented needs for metal ion separation technologies and sensors have been extensively documented by the Site Technology Coordination Groups. Appendix A lists 55 technology needs from a broad spectrum of DOE sites that potentially benefit from the research described herein. 


\subsection{Patents}

Prof. D. M. Roundhill of Texas Tech University filed one invention disclosure entitled "Derivitized Lignin for the Extraction of Heavy Metals." 


\subsection{Future Work}

It is our assertion that the development of improved metal ion sequestering agents can be greatly facilitated through the application of computational chemistry. Although this assertion remains to be demonstrated with the f-block metal ions, the PI has demonstrated the efficacy of this approach with other radionuclides. In collaboration with Drs. E. P. Horwitz and M. L. Dietz of Argonne National Laboratory, the application of molecular modeling led to the discovery of a more effective extractant for strontium- 90 . More recently, in collaboration with Drs. B. A. Moyer, R. A. Sachleben, and J. C. Bryan of Oak Ridge National Laboratory, the application of molecular modeling led to the discovery of a modified calix[4]crown- 6 architecture with enhanced cesium-137 selectivity. In both cases, the key prerequisite for these successful applications was understanding how the individual ligand donor groups interacted with the metal ion and incorporating this understanding within the framework of a molecular mechanics model.

At the end of this project have a molecular level understanding of the metal-amide interaction and have incorporated this understanding in the MM3 model, in other words, we have achieved the prerequisite for application of molecular modeling to the discovery of improved amide ligands. An important finding from this work is that significant improvements in the efficiency of diamide extractants for f-block metal ions are possible through modification of the ligand structure. Further research is needed to test this finding. As noted earlier, Prof. J. E. Hutchison at the University of Oregon has made progress toward the synthesis of a novel diamide structure that we predict to be preorganized for trivalent f-block metal ions. The design criteria developed in this study could be applied to identify other candidate architectures for metal ion receptors with multiple amide binding sites. The molecular mechanics model developed in this study could be used to screen these candidates prior to synthesis. Thus, an area of follow-on research is the design, synthesis, and testing of novel amide ligands for sequestering f-element metal ions.

Much of the current development of solvent extraction processes for f-block metal ion separations rests on the hypothesis that the diamide sequestering agents bind to the metal ion in a bidentate fashion. However, our research calls this assumption into question. Another area for further research is to examine in closer detail the nature of the diamide f-element interaction. Full elucidation of metal ion speciation in the organic phase remains a challenge.

During the first three years of this project we focused mainly on the amide donor group. However, as noted above, there are a number of other donor groups that have a known affinity for the f-block metal ions such as phosphine oxides, pyridine $\mathrm{N}$-oxides, catecholates, hydroxypyridinonates, and aminocarboxylates. An important target for future research is to understand how these donor groups interact with metal ions and incorporate this understanding within the framework of a molecular mechanics model. Such models will provide the capability to design ligand architectures containing these donor groups. This research is the subject of an FY-2000 renewal proposal to the Environmental Management Science Program, a collaborative effort between Pacific Northwest National Laboratory, Oak Ridge National Laboratory, the University of California-Berkeley, and the University of New Mexico. 


\section{Appendix A \\ Year 2000 Site Technology Needs Potentially Impacted by this Research}




\section{Appendix A \\ Year 2000 Site Technology Needs Potentially Impacted by this Research}

\section{Relevant Savannah River Site Technology Needs}

SR00-5022 Identify and Develop a Better Process to Remove Residual Pu from U Metal

SR00-4014 Basin Cleanup Technology

SR00-4013 Containment/Confinement Technologies

SR00-4012 Stabilization of Contaminated Equipment/Components/Surfaces

SR00-4004 Decontamination of Contaminated Concrete

SR00-3020 Innovative Technologies for Ash Basin Remediation

SR00-2054-S Develop Improved Radiochemical Analysis for High Ionic Strength Samples

SR00-2053-S Develop an Alternative Sorbent to Replace Monosodium Titanate for Sr and Actinide Removal

SR00-1014 Cleaning of Alpha Contaminated Launderables

SR00-1002 Treatment for MW Soils to Immobilize Radionuclides and RCRA Constituents for Disposal

\section{Relevant Rocky Flats Site Technology Needs}

RF-ER11 Real-Time Monitoring of Plutonium and Americium in Sewage Treatment Plant Influent RF-DD10 Improved Decontamination of Non-Porous Building Property and Structures

RF-DD09 Improved Decontamination of Porous Surfaces in Preparation for Building Demolition

\section{Relevant West Valley Site Technology Needs}

OH-WV902 Decontamination of High-Level Waste (HLW) Canisters

\section{Relevant Miamisburg Site Technology Needs}

OH-M904 Extraction of Plutonium and Thorium from Soils

\section{Relevant Fernald Site Technology Needs}

OH-F052 Long-Term Treatment of Leachate

OH-F044 K-65 Residue Stabilization Process for Final Remediation

OH-F043 Mixed Waste Projects

OH-F019 Enhanced Immobilization Mechanism of Uranium in Low Permeability Soils

\section{Relevant Argonne Site Technology Needs}

CH-DD07-99 Decontamination of Fixed Surface Contamination of Concrete (thin layer removal) 


\section{Relevant Brookhaven Site Technology Needs}

CH-MW06-99 Treatment of Radioactive Waste

CH-MW01-99 Treatment of Hg Mixed Waste From Chemical Holes

CH-SS04-99 Long-Term Groundwater Monitoring

CH-SS03-99 Treatment of Radioactive Contaminated Soils

CH-SS01-99 Remediation of Strontium-90 Contaminated Groundwater

\section{Relevant Idaho Site Technology Needs}

ID-S.2.06 Understanding the Physics and Chemistry of Metal Decontamination

ID-S.2.05 Understanding the Physics and Chemistry of Concrete Decontamination

ID-7.2.03 Decontamination of Concrete Walls, Floors, Ceilings, and Corners

ID-6.1.32 In Situ Stabilization Techniques to Isolate Metals and Radionuclides from the Biosphere, including both Surface and Deep Fractured Rock

ID-6.1.31 Development and Testing of Improved Compounds Suitable for Direct Injection for In Situ Stabilization

ID-2.1.56 Mercury Treatment for Aluminum Calcine

ID-2.1.40 Low Activity Waste Grout Sorbent Addition to Reduce Leachability

ID-2.1.28 Cs and Sr Removal from Newly Generated Liquid Waste

ID-2.1.06b Cs Removal from High Activity Waste

ID-2.1.06a TRU and Sr Removal from High Activity Waste

ID-2.1.06 TRU, Cs and Sr Removal from High Activity Wastes

\section{Relevant Hanford Site Technology Needs}

RL-DD021 Metal Decontamination and Recycling for the D\&D Program

RL-DD04 TRU Waste Fixatives for PFP

RL-DD03 Terminal Clean-Out and TRU Waste Decontamination of PFP

RL-MW04 Remote Decontamination of RH TRUW Debris to Support Reclassification into Non-TRUW Category

RL-SS24 Improved Ex Situ Treatment of Soils Contaminated with Lead and Other TCLP Metals

RL-SS23 Improved, Ex Situ Remediation of Chromium in Groundwater

RL-SS 12 Cost-Effective, In Situ Remediation in the Vadose Zone of One or More of the Following Radionuclides: Uranium, Plutonium, Cesium, Cobalt, and Strontium-90

RL-SS09 Improved, Real-Time, In Situ Detection of Strontium-90 in Groundwater

RL-SS08 Improved, Real-Time, In-Line Detection of Strontium-90 in Process Water

RL-SS07 Cost-Effective, In Situ Remediation of Strontium-90 in Groundwater

RL-WT061 Reactive Barriers to Contaminant Migration 


\section{Relevant Los Alamos Site Technology Needs}

AL-08-01-16-SC Cost Effective Treatment Technologies for TRU Soils and Sediments

AL-00-01-01-SC Treatment of Soil Containing PCBs, Radionuclides, Metals and Organics

AL-00-01-03-SC Cost-Effective Means of Characterization and Remediation of HE-Contaminated Soils, Surface Waters, and Groundwaters

AL-09-01-05-MW Mobile Analysis Methods for Hazardous Metals in TRU Waste

AL-07-01-12-DD Decontaminate and Decommission Radioactively Contaminated Facilities

AL-00-01-06-DD Effective Decontamination of Concrete

AL-09-01-29-NM Separation of Uranium from Plutonium using Ion Exchange Techniques

AL-09-01-43-NM Establishing a Path Forward for Economical Processing of Radioactive Neutron Sources

\section{Relevant PANTEX Site Technology Needs}

AL-07-06-04-SC In Situ Remediation of HE, Solvents, VOCs, SVOCs, Heavy Metals, and Landfill Materials 